\title{
Pernicious Performance Appraisals: A Critical Exercise
}

\author{
Paul L. Stepanovich \\ Professor of Management \\ Southern Connecticut State University \\ School of Business \\ 501 Crescent Street \\ New Haven, CT 06515 \\ 203-392-5849 \\ stepanovicp1@southernct.edu
}

\begin{abstract}
This article presents a pedagogical exercise where students can experience bias and chance in a performance appraisal process. Students in the role of Vice-presidents interview and make decisions regarding employment and pay for analysts. Student analysts are interviewed and either fired, promoted, or given pay increases based on the interview and the Vice-president's information. Ultimately, it is revealed that there is no difference in true performance among analysts and that all decisions were based on bias and chance. The article provides an extensive literature review and teaching notes to support the problems with the administrative use of performance appraisals.
\end{abstract}

Keywords: Performance appraisals, critical thinking, pedagogical exercise

\section{Introduction}

Performance appraisals (PA) present management scholars with a dilemma: they are ubiquitous in management practice yet they are routinely criticized in the management literature. The purpose of this article is to help students come to grips with this dilemma by providing an exercise where they can directly experience some of the issues. The focus will be on the administrative application of performance appraisals, where they are used in decisions related to pay, promotions, and terminations, and where it is essential that the appraisal be unbiased, fair, and accurate.

In this light, consider the following quote from W. E. Deming (1982/2000) regarding the PA:

It nourishes short-term performance, annihilates long-term planning, builds fear, demolishes team-work, nourishes rivalry and politics. It leaves people bitter, crushed, bruised, battered, desolate, despondent, dejected, feeling inferior, some even depressed, unfit for work for weeks after receipt of rating, unable to comprehend why they are inferior. (p. 102)

Deming was a recognized guru in the quality movement and famous for his critique of performance ratings, identifying them as one of management's deadly diseases. And he was not 
alone. Douglas McGregor (1957) was also critical of PAs when used for administration. He identified two deep roots to the problem. First, there is a "violation of the integrity of the personality," wherein managers are uncomfortable "playing God" and having to "judge the personal worth of a fellow man" (p.90). Second, there is a dehumanizing aspect; employees are objectified as products in an inspection process. Here, the manager's resistance to PAs stems from "an unwillingness to treat human beings like physical objects" (p. 90). Later, McGregor (1960/1985, Chap. 6) emphasized the problems associated with the variation in the standards of different judges, including not only bias and prejudice, but presumably, chance. In McGregor's words:

The answer given by an appraisal form to the question: 'How has $A$ done?' is as much a function of the superior's psychological make-up as of the subordinate's performance. If we then take these somewhat questionable data and attempt to use them to make fine discriminations between people for purposes of salary administration and promotions, we may create a pretty picture, but one which has little relation to reality. (p. 82)

So, Deming and McGregor had concerns, but, perhaps, the problems have since been solved. Unfortunately, Heil, Bennis, \& Stephens (2000, Chap. 5), in their review of McGregor's work, found that little had changed in the 25 years since McGregor's publications. They found that PAs stifle creativity, inhibit dialogue, label employees as losers, decrease self-esteem, encourage mediocrity, reduce and distort information flows, create a short-term focus, undermine vision and values, and destroy trust. And, as we will see in the literature review, current scholars reinforce this view.

Thus, given these concerns, a critique of the PA process warrants sufficient scrutiny in the management curriculum. And while students may read such critiques, it is another thing to experience them. What if the student is forced to make the difficult decisions regarding promotions and firings, or if the student is the victim of an unfair evaluation? The purpose of this paper is to present an exercise, the Pernicious Performance Appraisal, in which students have such experiences. In the exercise, all employees are truly equal in performance, yet their evaluation scores appear to be different due entirely to bias and chance.

While the exercise can be used to expose and reinforce the arguments against the performance appraisal process, it also makes a powerful critical thinking exercise. Such exercises challenge students to think outside the norm and to challenge assumptions. In this respect, the exercise joins the ranks of other critical thinking activities offered by Humphries and Dyer (2005), Meisel and Fearon (2006), and Stepanovich (2009). In this context, the exercise addresses a phenomenon noted by Alvesson and Willmott (1996), "When at work or in education, it s not unusual for practitioners or students of management to experience some twinges of discomfort about some aspect of the theory and/or practice of management" (p. 15).

\section{Review of the Literature}

Much of the literature concerns itself with biases and the psychometric accuracy of the evaluation process. Banks and Roberson (1985) compared the rater in the PA process to a psychometric test developer. They found that if we were to hold performance raters to the same standards as psychometricians, raters would fall woefully short. They highlight major issues with validity and contamination. Prendergast (1993) pointed to the problems of reneging (giving low ratings so the organizations does not have to pay bonuses), biases, fairness, and compression of ratings and rewards. Cook (1995) expands on the biases and adds those of politics, impression 
management (ingratiation), and undeserved reputation (image-polishing and public relation games). Campbell, Campbell and Chia (1998) reiterate the validity and bias issues and add the problems associated with system noise (an interdependence issue) and unintended consequences (shifting focus to what is measured and decreasing intrinsic motivation).

We have long been aware of cognitive biases such as representativeness, causality and attribution, availability, covariation and control, and overconfidence (e.g., Kahneman, Slovic, \& Tversky, 1982; Kahneman \& Tversky, 1973; Tversky \& Kahneman, 1974). Brown, Jackson, and Mowen (1980) and Bernardin (1989) focused on the fundamental attribution error. In the study by Brown et al., it was found that the error was present in the performance evaluation process for sales personnel, while Bernardin listed 22 external factors that need to be considered in a performance evaluation. Nathan and Alexander (1985) noted that PAs involve more than acquiring accurate observations; cognitive processing is essential. Bernardin, Hennessey, and Peyrefitte (1995) agree and suggest that reducing biases through specific practices will likely fail, stating, "all types of rating formats under study are subject to cognitive process distortions" (p. 70).

As Woehr and Feldman (1993) pointed out, judgment may precede memory. Raters judge first and recall second; raters find data to support what they want to do (confirmation bias). Martell and Leavitt (2002) found that performance-cue bias, where beliefs and expectations can bias judgment, persists even with behaviorally based ratings, in both laboratory and field studies. Again regarding performance-cue bias, Martell and Evans (2005) find evidence of the bias and propose an intervention to reduce it. Hanges, Braverman, and Rentsch (1991) found support for prior information bias in a lab setting. Both Lefkowitz (2000) and Varma and Pichler (2007) addressed the like-dislike effect, but Lefkowitz concludes that the bias is generally present, whereas Varma and Pichler argue that managers can separate affect from performance. Prior findings of bias, they argue, may be a reversal of cause and effect; that raters like the employee because they are better performers. However, Wayne and Liden (1995) found a significant similarity effect in a longitudinal study, where the similarity came before the effect. Regarding the politics of the process, both Longenecker (1986) and Poon (2002) found substantial evidence for a political component. Poon concluded that you cannot just train raters to counter the effects; you must change the social and political context. Finally, Scullen, Mount, and Goff (2000) found that over half of the variance in performance ratings were explained by idiosyncratic tendencies in the rater, that is, halo, leniency and rater by ratee interactions. They state, "Our results show that a greater proportion of variance in ratings is associated with biases of the rater than with the performance of the ratee" (p. 967). Ng, Koh, Ang, Kennedy, and Chan (2011) confirmed these findings.

Research has also addressed race and gender biases. Mobley (1982) found evidence for both race and gender bias in a field study. However, Mobley, and other researchers reporting similar findings (e.g., Tsui \& O'Reilly, 1989), were criticized for not controlling for other variables. Several studies then claimed that racial bias disappeared after adjusting for age, experience, cognitive ability, and education (Sackett \& Dubois, 1991; Waldman \& Avolio, 1991). The researchers admitted, however, that bias may be present in the control variables. Stauffer and Buckley (2005) take issue with such studies, pointing out that studies finding no bias are actually minimizing findings of bias by ignoring a rater-ratee race interaction effect. Their reevaluation of the Sackett and Dubois data revealed such an effect and, therefore, a racial bias.

There is also evidence for gender bias. Bowen, Swim, and Jacobs (2000) found pro-male biases when men were the raters. Chung (2001) found evidence that both genders will tend to 
rate successful male managers higher than successful women managers. Heilman, Wallen, Fuchs, and Tamkins (2004) found support for gender bias in stereotypically male jobs where, even if women are successful, there is a cost:

When acknowledged as successful they no longer are saddled with the image of being incompetent, but they may also pay a price. The price is social rejection ... and it appears to have definite consequences for evaluation and recommendations about reward allocation. [emphasis added] (p. 426)

Lyness and Heilman (2006) showed that women managers in line positions were not only rated lower than all other managers (women in staff positions and men in both line and staff positions), but also had higher average levels of performance when promoted, that is, they had to clear a higher bar. Furthermore, they emphasized the importance of detailed study, arguing that bias can exist in pockets (e.g., line positions) when there is no overall main gender effect. Schein (2007) provides disturbing longitudinal data illustrating the tenacity of gender bias in management. In the 1970s, men were perceived by both men and women as being more suited to management positions. By the 1990s, and as recently as 2006, the attitudes of women concerning managers had changed, whereas those of men had not. Men still associated management characteristics with men, not women.

\section{Other Issues}

The research seems clear: we need to be wary of PAs given the host of problems they contain. This alone would justify the Pernicious Performance Appraisal exercise. However, before presenting the exercise, I would like to explore several related topics, ones not typically found in a review of performance appraisals. First, as it stands, much of the literature either states directly or implies that if we can just accurately measure performance, all will be well. If, however, the claim by Tziner and Kopelman (2002) is correct, that "decades of research on the psychometric properties of various appraisal methods have not demonstrated conclusively...the existence of a format that is most reliable and valid" (p. 480), then we have not progressed appreciably on Banks and Roberson's (1985) critique. And even if we had, it is not that simple. Campbell et al. (1998) pointed out that training and psychometric improvements will help evaluators agree on facts but they do not address the causes of bias, which they claim are position based. This is similar to McGregor's root causes: violation of the integrity of the personality and dehumanization. And, Poon (2002) argued that we would have to change an organization's social and political structures to eliminate potentially negative political aspects of a PA, which is, admittedly, a difficult task.

Second, research that tries to make PAs more objective and accurate ignores other dimensions such as the interdependence and multidimensionality aspects of activities mentioned earlier. It also, perhaps, underestimates the problems of philosophy and deeper cognitive functioning. Even if we are measuring performance 'objectively,' there are philosophers and behavioral scientists who argue that no such thing is possible, that every objective measure can be traced back to insupportable assumptions about what is 'good' or of 'value.' Scholars with a constructionist or postmodern bent will likely find little value in the empirical line of research addressing PAs.

Third, there is a general problem with quantitative studies examining whether performance appraisals are biased. Statistical analyses across large samples address measures of central tendency. In this case, off-setting biases can get lost in the error term. While this may be fine for a sociological question about societal bias, it will not do for administrative PAs. At this 
level, where we are concerned with individual inequities or issues of justice and fairness, we must look at each individual case. This was the issue when Lyness and Heilman (2006) emphasized the importance of detailed study in gender bias. What is needed is research looking at the individual experience, which, in general, would require more qualitative, ethnographical research out of the constructionist-phenomenological domain. The literature is relatively silent in this area (Longenecker, 1986; Bradley \& Ashkanasy, 1997).

Fourth, there is a concern with the application of PAs. Pfeffer and Sutton (2006, Chap. 5) review the problems of incentives, a direct outcome of the administrative use of PAs. They cite many problems, but emphasize problems with the self-enhancing effect and complexity. Selfenhancement is the belief by many that they are above average. In these cases, average or below average ratings will be a disincentive. Complexity has to do with interdependencies, either with peers or external system factors. In their words, "when work settings require even modest interdependence and cooperation, as most do, dispersed rewards have consistently negative consequences on organizations" [emphasis added] (p. 128). Similarly, "simple palliatives like pay for performance aren't likely to fix all - or even any - of your performance problems and may instead drive up costs, hamper cooperation, and stifle new ideas" (p. 129). Dispersed rewards and pay-for-performance systems are an integral part of the PA process.

Fifth and finally, McGregor's earlier quote about the inability of PAs to discriminate among individuals raises the issue of chance. Indirectly, chance is at work in the system factors of Campbell et al. (1998) and in Bernardin (1989). However, chance, as a direct effect in PAs, is generally absent from the critiques of PA. Where random factors were incorporated, they explained between 10 and 30 percent of the variance (Scullen et al., 2000; Viswesvaran, Ones, \& Schmidt, 1996). In a more general sense, March and Sutton (1997) and Parnell and Dent (2009) argue for a greater role of chance in performance. March and Sutton (1997) argued that we tend to 1) oversimplify complex worlds, translating complex webs of causality into simple causes, and 2) justify performance after the fact, succumbing to recall bias. The justification hides the fact that the true cause may have been chance. Similarly, Parnell and Dent (2009) point out how the role of chance is often ignored in research. Scholars tend to view unexplained variance as ignorance - if we just added more independent variables we would explain everything - rather than chance.

The exercise that follows was designed to illustrate aspects of the critiques above. It will highlight, for example, how gender bias, a primacy effect, rater reliability, the fundamental attribution error, and chance can come together to make equally performing individuals appear different. For participants, it will also simulate the personal, individual experiences found in the PA process, thereby providing a more meaningful connection to the issues. In short, it will demonstrate how bias and chance can infuse the PA process, making it effectively impossible to accurately measure an individual's true performance, while at the same time giving students pause, providing more grist for the critical thinking mill.

\section{The Exercise}

The Pernicious Performance Appraisal simulates a decision process whereby a vicepresident (VP) must evaluate five financial analysts in a forced ranking system. As background, the five analysts were hired with the understanding that one of them would be discharged after a three-year trial period. In addition, there is a promotion opportunity for one and the others are to receive a $10 \%$ raise, $4 \%$ raise, or no raise. The analysts reported to, and were evaluated by, different supervisors, which is the reason the VP is to make the decision. The VP will review 
portfolios containing the analyst's education, a summary note by the supervisor, six biannual evaluation scores, and a note from human resources. The analysts receive a script providing information on their history and performance scores over the past three years. In the simulation, the VP interviews each analyst and makes the decision, noting the rationale. There are six students per group. Extra students can be assigned the role of anthropologist, moving around during the exercise observing and noting behaviors. Table 1 summarizes the roles, materials, and responsibilities.

Table 1. Roles, Materials, and Responsibilities

\begin{tabular}{|l|l|l|}
\hline Role & Materials & Responsibilities \\
\hline V.P. HR & Instructions (1) & Interview each analyst individually; make \\
& Analyst Portfolios (5) & decision with justifications; announce \\
Summary of Ratings (1) & decisions \\
\hline Analysts & Instructions (1) & \\
(5 per group) & Script (5) & Be interviewed; receive decision \\
\hline Anthropologists & Instructions (1) & Make observations of the groups \\
\hline
\end{tabular}

The exercise is designed for a two and a half hour class of 18-28 students but can be adapted for two seventy-five minute classes. With 28 students, there are four groups playing out the scenario simultaneously, with four students acting as anthropologists. The instructions, portfolios, and analyst scripts are identical for each group except for the six semiannual performance evaluation scores for each analyst.

The performance evaluation scores were generated by a multiple regression equation that uses the following variables to adjust the true base score of five for each analyst:

1. Internal Variability: Each analyst is assigned a degree of performance variability, representing the role of system structure and chance.

2. Prior Evaluation: In this case the supervisors will vary on the degree to which each period's evaluation was influenced by the prior period. It is used to simulate prior information bias, a recency or halo effect, or performance-cue bias.

3. Systems Factors: This is the degree to which the supervisor is able to adjust for external structural factors in analyst performance. Sometimes the supervisor blames or credits the analyst for system effects, committing the fundamental attribution error.

4. Interaction Effect: To simulate complexity, there is a multiplicative interaction between Prior Evaluation and Systems Factors.

5. Rater Reliability: Supervisors vary in their consistency, increasing variability in the ratings. This represents intrarater or interrater reliability. 
6. Gender Bias: The supervisors vary in their direction and degree of gender bias.

As indicated, although each analyst's true score is a five on a 10-point scale, their performance scores exhibit variation caused solely by bias and chance, as generated by the regression model. Figure 1 illustrates the variation for group 1. While each group has different values, there will be some similarities. For example, Mary's evaluations, in general, are lower due to a combination of factors. Her supervisor was gender biased against women and he had difficulty separating out system effects (he blamed her when the system conspired to lower her performance). Terry, on the other hand, benefits from gender bias.

Figure 1. Summary of Analyst Ratings (Part of the VP's package, Group 1)

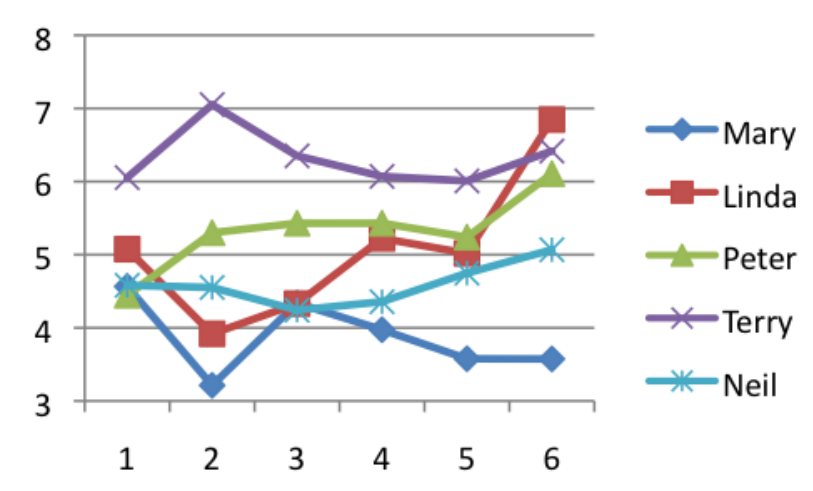

\section{Materials, Process, Timing}

The materials required for the exercise include instructions for participants, analyst portfolios, a summary of analyst ratings, analyst scripts, and a decision form (see Appendix). The steps include introducing the exercise and selecting the groups (10-15 minutes), providing instructions (15-20 minutes), conducting interviews (35-40 minutes), making the decision (15 minutes), announcing the decisions (10 minutes), and summarizing results (10-15 minutes). This takes about two hours leaving approximately 30 minutes for discussion. Assigning instructions, portfolios, and scripts to be read before class can extend discussion time.

\section{Introduction and Decisions}

Students are told that the purpose of the exercise is to explore possible variation in the performance evaluation process. Background is given regarding the five hires for four positions, specifying that one analyst will be fired, one promoted, and the others given varying levels of raises. In a class of 24-28, four students, who have exhibited leadership roles, are asked to volunteer to be a vice president who will conduct the performance evaluations. Five analysts are then assigned to each of the four VPs. Students not placed in a group are assigned the role of anthropologist.

After reviewing the materials, each VP sets up an interviewing area and the analysts wait in the hallway. Each VP calls in each analyst for a five-minute interview (four sessions are occurring concurrently). This gives the VP an opportunity to clarify any questions from the portfolios and time for the analysts to make their case for promotion. The analysts are told not to 
stray too far from the script. After the interviews, the VPs make their decisions, noting their reasons on the decision form. They then meet with each analyst individually to announce their decision. This ends the exercise.

\section{Debriefing and Discussion}

I write the results from each group on the board, recording who was fired, promoted, and given a raise. It soon becomes apparent that there are differences across the groups, but that there also appear to be commonalities. For example, as mentioned earlier, Mary is fired more often than others. I ask the VPs to explain the rationale for their decisions. In the course of this discussion, it becomes obvious that the ratings were different not only within each group, but also between groups. For example, Mary's ratings in Group 1 were not the same as her ratings in Group 3. At this point, I start to get questions as to why this is so - why the ratings are different both among analysts and also across groups.

After a brief exploration of why there may be differences, I announce that there are, in fact, no differences in the performance of any of the analysts, either within the groups or between them. Each analyst in each group performed at a 'true' level of a five on a ten-point scale for each of the six evaluation periods. All the differences seen on the portfolios and scripts were due to factors unrelated to an individual's performance. Thus, the analyst who was promoted did not earn the promotion, the person who was fired did not deserve to be fired, and there were no differences in performance that could justify a difference in raises. At this point I turn to the teaching notes.

\section{Teaching Notes}

In my experience, students resist the idea that performance differences are not 'real.' In their minds, it is obvious that there are actual, true performance differences and a supervisor's evaluation rating accurately, for the most part, reflects those differences. The overarching lesson in the exercise is that we do not know if the differences are, in fact, real. We would have to eliminate all bias and chance from the evaluation, from each specific individual performance appraisal. The rigorous research required to remove these effects is simply not done and, therefore, we cannot know the degree to which rating differences reflect bias and chance. To emphasize the point, I focus on three main lessons: review of biases, induction and chance, and justification versus prediction.

\section{Review of Biases}

In the exercise, the regression term Prior Evaluation is used to capture information bias, the recency effect, and performance-cue bias. In the simulation, some supervisors are swayed by prior ratings and recent performance while others are not, causing variation in the performance ratings. But, these biases only represent a few of a host of potential biases. One could add primacy and halo effects, selective perception, memory and hindsight biases, context dependence, contrast bias, and confirmation bias (summarized in Plous, 1993). We could also add similarity and like-dislike effects (Wayne \& Liden, 1995; Lefkowitz, 2000; and Varma \& Pichler, 2007). Wikipedia, however one feels about its veracity, lists over one hundred cognitive biases, most of which could be present in a performance appraisal.

The variable System Factors refers to attribution theory, specifically the degree to which 
the supervisor commits the fundamental attribution error. Some supervisors will fall prey to the error more than others. Since all performance is a mix of external and internal influences, the danger is to wrongly punish employees for system or situational factors outside of their control. If managers see these external factors, then they will more likely avoid this danger.

The final bias term in the exercise is gender bias. Again, gender bias should be taken as representative of other possible biases such as age, race, and ethnicity. While there is extensive research about discrimination, it tends to focus on patterns over time as opposed to individual performance appraisals. What is important here is whether a specific supervisor is biased for or against a specific employee at a point in time. Large sample studies where biases average out are not applicable.

Discussion questions can address whether biases are present, to what degree, and whether the evaluator is aware of them. And, perhaps, most important, whether they can be eliminated from the process. I have students react to Scullen et al. (2000), specifically their conclusion that biases explain more variation than performance. In addition, students are also asked to list and illustrate through example the cognitive biases that can play havoc with performance evaluations, encouraging them to relate them to their experiences with evaluations (whether in industry or education). Has a manager ever been biased toward them, positively or negatively?

\section{Induction and Chance}

The next lesson addresses the role of chance in the performance appraisal process. This is an issue of induction. In the exercise, a regression model is used to take evaluation ratings from a known constant, where all analysts perform at the same level, to the appearance of variation, where some analysts appear to have performed better than others. Part of the variation is due to bias, as discussed in the first lesson, but there is also variation due to chance. The exercise uses Monte Carlo simulation to reflect chance in the evaluation process. Values from the variable Individual Variation are selected randomly from a uniform distribution while values from System Factors and Gender Bias are drawn from a normal distribution. Although chance is often ignored in research (Parnell \& Dent, 2009), to support chance as a factor in organizational performance, we will look to organizational theory and statistical process control theory.

Organizational theorists Cohen, March, and Olsen (1972) proposed a garbage can model of organizational choice that explicitly attempts to capture the complexity and chance factors inherent in organizational decisions. Essentially, decision makers, the problems available, and the choices for solution are in constant flux driven by random elements in the organization. Over time, decision makers attach themselves to problems, employing a solution set, but may then drop the problem, only to be replaced by another decision maker later. It is a complex web of interactions occurring over time. Decisions and their associated participants, choices, and solutions are an integral part of what the performance appraisal is evaluating. Part of the problem lies in how we remove chance in hindsight. March and Shapira (1987), in investigating risk taking, concluded:

In historical perspective, we have no difficulty distinguishing those who have been brilliant risk takers from those who have been foolish gamblers, however obscure the difference may have been at the time they were making their decisions. Post hoc reconstruction permits history to be told in such a way that 'chance' -- either in the sense of genuinely probabilistic phenomena or in the sense of unexplained variation -- is minimized as an explanation... (pp. 1413-1414) 
So, according to at least one major organizational theory, variation due to chance is inherent in performance.

Statistical process control theory also incorporates variation and chance. In manufacturing processes, variation is inevitable. At each step in the production process, many factors come together in complex ways to randomly affect the output of that portion of the process. The question production operators face is: when is the variance a problem? The effects of the complex system create a natural level of variation in the outcomes, such that any attempt to explain the variance is not only a waste of time, but harmful to the system. This was precisely the case in the Hawthorn plant in the 1920's when Walter Shewhart, physicist and statistician, was asked to investigate failures to improve quality; the engineers were trying to fix every defect in the telephones as they came off the assembly line. Shewhart (1939/2000) recognized that trying to address natural variation with individual fixes was not going to work. As a result, he developed the control chart in order to differentiate between natural variation and exceptional variation.

Shewhart's control chart is ubiquitous in manufacturing today and a staple of all quality and ISO standards. Unfortunately, both Shewhart, and his colleague, W. E. Deming, claimed that control charts were also essential in managing people (Deming, 1994, pp. 37-38). Variation in employee performance is a given and, for these scholars, without control charts, there is no way for a manager to know if performance variation is natural (caused by the complex interactions of many factors) or caused by the individual. Individuals could easily become the scapegoat for problems caused by the system.

If chance is inherent in performance systems, then cognitive biases again become a specter. When chance is at work, we are inclined to miss it. Randomness error is our proclivity to find patterns and causes in random data. Hake and Hyman (1953) did some of the early work on superstitious learning, and more recently, Chabris \& Simons (2010) present research on the illusion of cause and pattern perception, where we extract meaning from random data. In addition, we are also not wired well to appropriately understand cause and effect. Plous (1993, Chapter 15) provides a summary of the problems in this area, including illusory correlation and 'causalation.'

In addition, there is another element of chance not captured formally in this exercise. In the real world, there would likely be an element of chance in the assignment of supervisors. In the exercise, Mary, for example, is assigned to a gender-biased supervisor, and this holds for each of the four groups. Taleb (2005, pp. 49-52), to illustrate the role of chance, proposes a Monte Carlo thought experiment where we rerun history to imagine how things might have been different. What if Mary were assigned a gender-neutral supervisor or one inclined to rate women higher? If the random assignment of analysts to supervisors were incorporated into the regression equation, there would be an even larger degree of variation in the results.

For this lesson, in discussions, I appeal to student experiences with evaluations. Have they ever received different ratings (compared to peers or over time) when there were no substantial differences in performance? How would they know if true performance differed? Did they ever receive a lower evaluation than what they deserved? Did someone else receive a higher raise when it was not earned? Can evaluations be completely objective? What are some possible consequences? Can they imagine rerunning their life history and ending up with different evaluation experiences?

\section{Justification versus Prediction}


The third lesson has to do with justification versus prediction, that is, how often data are used to justify decisions rather than to make predictions based on evidence with predictive validity. The earlier quote from March and Shapira (1987) is again relevant and bears repeating:

In historical perspective, we have no difficulty distinguishing those who have been brilliant risk takers from those who have been foolish gamblers, however obscure the difference may have been at the time they were making their decisions. (pp. 1413-1414)

In the exercise, if the VP is only provided the evidence in Figure 2a, it would behoove her to promote Terry, fire Mary, give the $10 \%$ raise to Peter, the $4 \%$ to Linda, and no raise to Neil. The data can easily be used to justify the decisions. The problem, of course, is that there is no evidence that the differences are meaningful in predicting future performance, enough to justify the varying levels of rewards.

\section{Figure 2. Average Performance Ratings}
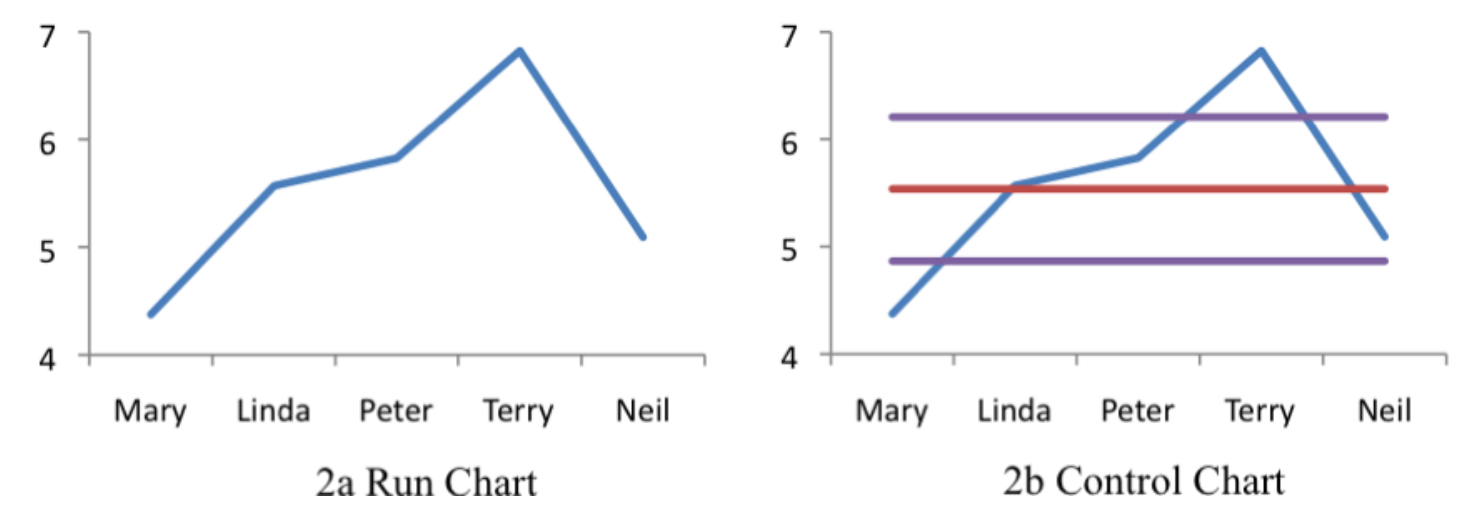

If the VP is familiar with statistical process control, a first step might be to place control limits on the data (Figure 2b). This suggests that there are no differences among Linda, Peter, and Neil. The differences in their performance ratings are due to natural system variation and should be ignored; they should share equally in any raise. Terry and Mary, however, are outside the limits. Terry's performance appears to be exceptional while Mary's appears to be a problem and both require investigation. In Terry's case, we would attempt to learn why Terry is doing well and transfer that knowledge to the other analysts. For example, if we learn that Terry is a statistician and applies it frequently, then, perhaps we can improve the performance of the other analysts by providing training in statistics. Similarly, an investigation might reveal that Mary had a limited background in accounting and this was hindering her performance. She should be given training in accounting.

If this were the case, however, is it fair to reward Terry for ignorance on the part of the organization as to the importance of statistics in the analyst's job? If the organization had known this and hired analysts with an equally strong background in statistics, then Terry would not have stood out. Similarly, is it fair to punish Mary for the organization's ignorance of the importance of accounting in the position? If all the other analysts had a similar deficiency, then Mary would not have stood out. In both cases, the organization would be rewarding or punishing based on the organization's hiring process, not the individual's performance.

However, there is a problem with using this approach. In the exercise, when the investigations are conducted for Terry and Mary, the findings should reveal that the differences were due to bias. The danger is that the investigator would find differences in the familiarity 
Terry and Mary had with statistics and accounting, but these would have had nothing to do with performance. They were spurious results of bias. It would take an astute investigator (or a disciplined one) to not attribute Terry's success and Mary's failure to personal characteristics.

Thus, if there are meaningful differences in performance and they are not due to bias, chance, or structural differences, then the onus is on the supervisor to show that the difference has predictive validity. This would require rigorous, experimental, longitudinal research designs. And, then they would only apply if the prediction is relevant. For example, the prediction would not be relevant when promoting someone in a technical position to management. The past performance would not be applicable.

Discussions regarding justification and prediction center on the fairness of rewarding and punishing based on performance measures that do not have predictive validity. They also deal with the feasibility of conducting the research required for such validity and, short of this level of evidence, what we can say about performance ratings. Is it true that, as McGregor said [and Scullen et al. (2000) support], PAs say more about the rater than the ratee?

\section{Applications and Experience}

When I use the Pernicious Performance Appraisal exercise in MBA management classes, student responses are mixed. In a typical class of 30 students, there are usually three or four for whom this exercise is nothing new. They have been victims of past injustices and know that evaluations are inherently biased and subjective. In reflection papers, they report feeling vindicated by the evidence against evaluations and validated by the writings of scholars such as McGregor, Deming, Pfeffer, and Bennis.

On the other hand, there are usually three or four students who are unmoved by the exercise. They remain convinced that performance evaluations are sound, that they accurately reflect true differences in individual performance, and that they, ultimately, do no harm certainly not to the extent of Deming's opening quote. The remaining students fall between these two extremes. Prior to the exercise, most of these students had an uneasy feeling about evaluations but had never explicitly considered the problems. After the exercise, however, they appear convinced that there are major problems with the process and want to explore alternatives. And, while they are reluctant to eliminate evaluations entirely, I believe they are more skeptical of their validity. And, as a critical thinking exercise, that is all I ask.

\section{References}

Alvesson, M., \& Willmott, H. (1996). Making sense of management: A critical introduction. London: Sage.

Banks, C. G., \& Roberson, L. (1985). Performance appraisers as test developers. Academy of Management Review, 10, 128-142.

Bernardin, H. J. (1989). Increasing the accuracy of performance measurement: A proposed solution to erroneous attributions. Human Resource Planning, 12, 239-250.

Bernardin, H. J., Hennessey, H. W., \& Peyrefitte, J. (1995). Age, racial, and gender bias as a function criterion specificity: A test of expert testimony. Human Resource Management Review, 5, 63-77.

Bowen, C., Swim, J. K., \& Jacobs, R. R. (2000). Evaluating gender biases on actual job performance of real people: A meta-analysis. Journal of Applied Social Psychology, 20, 2194-2215. 


\section{Pernicious Performance Appraisals}

Bradley, L. M., \& Ashkanasy, N. M. (1997). Using theory to structure qualitative research: An investigation of gender and identity in performance appraisal. Academy of Management Proceedings, 386-390.

Campbell, D. J., Campbell, K. M., \& Chia, H. (1998). Merit pay, performance appraisal, and individual motivation: An analysis and alternative. Human Resource Management, 37, 131-146.

Chabris, C. F., \& Simons, D. J. (2010). The invisible gorilla: And other ways our intuitions deceive us. New York: Crown.

Chung, J. (2001). The effects of rater sex and rate sex on managerial performance evaluation. Australian Journal of Management, 26, 147-161.

Cohen, M. D., March, J. G., \& Olsen, J. P., (1972). The garbage can model of organizational choice, Administrative Science Quarterly, 17(1), 1-25.

Cook, M. (1995). Performance appraisal and true performance. Journal of Managerial Psychology, 10:7, 3-7.

Deming, W. E. (1982/2000). Out of the crisis. Cambridge, MA: The MIT Press. (Original work published in 1982).

Deming, W. E. (1994). The new economics: For industry, government, education, ( $2^{\text {nd }}$ ed.). Cambridge, MA: Massachusetts Institute of Technology Center for Advanced Educational Services.

Hake, H. W., \& Hyman, R. (1953). Perception of the statistical structure of a random series of binary symbols. Journal of Experimental Psychology, 45, 64-74.

Hanges, P. J., Braverman, E. P., \& Rentsch, J. R. (1991). Changes in raters' perceptions of subordinates: A catastrophe model. Journal of Applied Psychology, 76, 878-888.

Heil, G., Bennis, W., \& Stephens, D. C. (2000). Douglas McGregor, revisited: Managing the human side of enterprise. New York: John Wiley \& Sons.

Heilman, M. E., Wallen, A. S., Fuchs, D., \& Tamkins, M. M. (2004). Penalties for success: Reactions to women who succeed at male gender-typed tasks. Journal of Applied Psychology, 89, 416-427.

Humphries, M. T., \& Dyer, S. (2005). Introducing critical theory to the management classroom: An exercise building on Jermier's "Life of Mike". Journal of Management Education, 29, 169-195.

Kahneman, D., Slovic, P., \& Tversky, A. (Eds.) (1982). Judgment under uncertainty: Heuristics and biases. New York: Cambridge University Press.

Kahneman, D., \& Tversky, A. (1973). On the psychology of prediction. Psychological Review, $80,237-251$.

Lefkowitz, J. (2000). The role of interpersonal affective regard in supervisory performance ratings: A literature review and proposed causal model. Journal of Occupational and Organizational Psychology, 73, 67-85.

Longenecker, C. O. (1986). On the politics of performance appraisal: A qualitative study of executives as raters. Academy of Management Proceedings, 260-263.

Lyness, K. S., \& Heilman, M. E. (2006). When fit is fundamental: Performance evaluations and promotions of upper-level female and male managers. Journal of Applied Psychology, 91, 777-785.

March, J. G., \& Shapira, Z. (1987). Managerial perspectives on risk and risk taking. Management Science, 33, 1404-1418.

March, J. G., \& Sutton, R. I. (1997). Organizational performance as a dependent variable. Organizational Science, 8, 698-706. 
Martell, R. F., \& Evans, D. P. (2005). Source-monitoring training: Toward reducing rater expectancy effects in behavioral measurement. Journal of Applied Psychology, 90, 956963.

Martell, R. F., \& Leavitt, K. N. (2002). Reducing the performance-cue bias in work behavior ratings: Can groups help? Journal of Applied Psychology, 87, 1032-1041.

McGregor, D. (1957). An uneasy look at performance appraisal. Harvard Business Review, 35(3), 89-94.

McGregor, D. (1960/1985). The human side of enterprise: $25^{\text {th }}$ anniversary printing. Boston: McGraw-Hill. (Originally published in 1960)

Meisel, S. I., \& Fearon, D. S. (2006). "Choose the future wisely": Supporting better ethics through critical thinking. Journal of Management Education, 30, 149-176.

Mobley, W. H. (1982). Supervisor and employee race and sex effects on performance appraisals: A field study of adverse impact and generalizability. Academy of Management Journal, 25, 598-606.

Mowen, J. C., Brown, S. W., Jackson, D. W.,(1980-1981). Cognitive biases in sales management evaluations. Journal of Personal Selling \& Sales Management, 1, 83-89.

Nathan, B. R., \& Alexander, R. A. (1985). The role of inferential accuracy in performance rating. Academy of Management Review, 10, 109-115.

Ng, K., Koh, C., Ang, S., Kennedy, J. C., \& Chan, K. (2011). Rating leniency and halo in multisource feedback ratings: Testing cultural assumptions of power distance and individualism-collectivism. Journal of Applied Psychology, 96(5) 1033-1044. April 11. doi: $10.1037 / \mathrm{a} 0023368$.

Parnell, J. A., \& Dent, E. B. (2009). The role of luck in the strategy-performance relationship. Management Decision, 47, 1000-1021.

Pfeffer, J., \& Sutton, R. I. (2006). Hard facts, dangerous half-truths, and total nonsense: Profiting from evidence-based management. Boston: Harvard Business School Press.

Plous, S. (1993). The psychology of judgment and decision making. New York: McGraw-Hill.

Poon, J. M. L. (2002). Effects of performance appraisal politics on job satisfaction and turnover intention. Personnel Review, 33, 322-334.

Prendergast, C. (1993). Discretion and bias in performance evaluation. European Economic Review, 37, 355-365.

Sackett, P. R., \& DuBois, C. L. Z. (1991). Rater-ratee race effects on performance evaluation: Challenging meta-analytic conclusions. Journal of Applied Psychology, 76, 873-877.

Schein, V. E. (2007). Women in management: Reflections and projections. Women in Management Review, 22, 6-18.

Scullen, S. E., Mount, M. K., \& Goff, M. (2000). Understanding the latent structure of job performance. Journal of Applied Psychology, 85, 956-970.

Shewhart, W. A. (1939/1980). The economic control of quality of manufactured product. American Society for Quality Control. (Original work published 1939)

Stauffer, J. M., \& Buckley, M. R. (2005). The existence and nature of racial bias in supervisory ratings. Journal of Applied Psychology, 90, 586, 591.

Stepanovich, P. L. (2009). The lobster tale: An exercise in critical thinking. Journal of Management Education, 33, 725-746.

Taleb, N. N. (2005). Fooled by randomness: The hidden role of chance in life and the markets. New York: Random House. 
Tsui, A. S., \& O’Reilly, C. A. (1989). Beyond simply demographic effects: The importance of relational demography in superior-subordinate dyads. Academy of Management Journal, $32,402-423$.

Tversky, A., \& Kahneman, D. (1974). Judgment under uncertainty: Heuristics and biases. Science, 185, 1124-1131.

Tziner, A., \& Kopelman, R. E. (2002). Is there a preferred performance rating format? A nonpsychometric perspective. Applied Psychology: An International Review, 51, 479-503.

Varma, A., \& Pichler, S. (2007). Interpersonal affect: Does it really bias performance appraisals? Journal of Labor Research, 28, 397-412.

Viswesvaran, C., Ones, D. S., \& Schmidt, F. L. (1996). Comparative analysis of the reliability of job performance ratings. Journal of Applied Psychology, 81, 557-574.

Waldman, D. A., \& Avolio, B. J. (1991). Race effects in performance evaluations: Controlling for ability, education, and experience. Journal of Applied Psychology, 76, 897-901.

Wayne, S. J., \& Liden, R. C. (1995). Effects of impression management on performance ratings: A longitudinal study. Academy of Management Journal, 38, 232-260.

Woehr, D. J., \& Feldman, J. (1993). Processing objective and question order effects on the causal relation between memory and judgment in performance appraisal: The tip of the iceberg. Journal of Applied Psychology, 78, 232-241. 


\section{Appendix}

\section{Participant Instructions}

\section{Vice President Instructions}

Three years ago, the organization - of which you are the Vice President of Human Resources - hired five financial analysts for four positions. Each new employee understood that one of their cohort would be fired after three years. Because the five analysts report to three different supervisors, you are to make the decision.

You have a portfolio of the employees, which gives their education, their evaluation scores, a summary note by the supervisor, and a note from human resources. You will review the analysts' files and then interview them (5 minutes). After the interviews, you will make your decision as to who will be let go. You also will need to select one of the five to be promoted to supervisor. Of the remaining three, one will receive a $10 \%$ raise, one a $4 \%$ raise, and one will not receive any raise. You will then meet with the analysts and tell them your decisions. You will be asked to justify your decisions, so record your decisions and notes on the form provided.

\section{Employee Instructions}

You were one of five financial analysts hired three years ago. You came in with the understanding that only four analysts would be retained after three years. It is time to make the decision as to who stays and who goes.

Since the five analysts reported to three different supervisors, the Vice President of Human Resources will make the decision. He/she will review the reports of each of the supervisors for each analyst and make the final decision as to who is fired. In addition, there is an opening for a supervisor slot so one of the five employees will be promoted. Of the three remaining, one will be given a $10 \%$ increase, one $4 \%$ (cost-of-living), and one will receive no raise. There are no other alternatives. The Vice President is forced to place an employee into each slot.

You are to review your script and prepare for an interview with the Vice President. Please stick to the information on the script in the interview (you may take the script to the interview). The VP does not have the script, only the reports of your supervisor.

After each of the five employees is interviewed, the VP will make the decision and then share it with you.

\section{Analyst Portfolios (Part of the VP's package)}

\section{Group 1}

\section{ID No.: 3542 (Mary)}

$\begin{array}{ll}\text { Department: } & \text { Investment Analysis } \\ \text { Division: } & \text { Finance } \\ \text { Years Service: } & 3 \\ \text { Supervisor: } & 038 \text { (Mark) }\end{array}$

Education: $\quad$ MBA

Harvard

B.S. Yale, mathematics

Supervisor's Summary:

At the outset it was clear to me that Mary did not have the skills required for the position. This was surprising given her degree in mathematics although I understand her interest lay in typology

\begin{tabular}{|c|c|c|c|c|c|}
\hline \multicolumn{6}{|c|}{ Performance Evaluation Ratings } \\
\hline \multicolumn{2}{|c|}{$1^{\text {st }} \mathrm{Yr}$} & \multicolumn{2}{c|}{$2^{\text {nd }} \mathrm{Yr}$} & \multicolumn{2}{c|}{$3^{\text {rd }} \mathrm{Yr}$} \\
\hline Dec & June & Dec & June & Dec & June \\
\hline 4.57 & 3.21 & 4.34 & 3.97 & 3.58 & 3.57 \\
\hline
\end{tabular}
and not analytics. This job requires an analytical mind and she doesn't have it. Beyond this, Mary performed consistently and was able to complete her projects. She did, however, take significant time off to attend to family matters. In a few instances, I feel this hindered our department's performance.

Human Resource Note: There are several complaints in the supervisor's file regarding gender discrimination. None have been sufficiently documented to warrant official action.

\section{ID No.: 3543 (Linda)}

$\begin{array}{ll}\text { Department: } & \text { Investment Analysis } \\ \text { Division: } & \text { Finance } \\ \text { Years Service: } & 3\end{array}$

Education: $\quad$ M.S. Finance

Univ of Southern Calif 
$\begin{array}{lll}\text { Supervisor: } & 019 \text { (Henry) } \quad \text { B.S. USC Finance }\end{array}$

Supervisor's Summary:

Linda does good work - not always outstanding.

I am concerned with her consistency. It is

difficult to predict her performance review-to-

review.

\begin{tabular}{|c|c|c|c|c|c|}
\hline \multicolumn{5}{|c|}{ Performance Evaluation Ratings } \\
\hline \multicolumn{2}{|c|}{$1^{\text {st }}$ Yr } & \multicolumn{2}{|c|}{$2^{\text {rd }} \mathrm{Yr}$} \\
\hline Dec & June & Dec & June & Dec & June \\
\hline 5.08 & 3.92 & 4.33 & 5.22 & 5.02 & 6.85 \\
\hline
\end{tabular}

Human Resource Note: This supervisor has had several complaints from subordinates regarding unfair evaluations. There is insufficient evidence, however, to warrant action.

ID No.: 3544 (Peter)

$\begin{array}{llll}\text { Department: } & \text { Investment Analysis } & & \\ \text { Division: } & \text { Finance } & \text { Education: } & \text { B.S. Accounting } \\ \text { Years Service: } & 3 & & \text { Univ of Massachusetts } \\ \text { Supervisor: } & 054 \text { (Jennifer) } & \end{array}$

Supervisor's Summary:

Peter is an excellent analyst. Although I do not work with Peter directly I am told that his performance is consistently above average. I have noted a few projects where his above average

\begin{tabular}{|c|c|c|c|c|c|}
\hline \multicolumn{5}{|c|}{ Performance Evaluation Ratings } \\
\hline \multicolumn{2}{|c|}{$1^{\text {st }} \mathrm{Yr}$} & \multicolumn{2}{|c|}{$2^{\text {nd }} \mathrm{Yr}$} & \multicolumn{2}{c|}{$3^{\text {rd }} \mathrm{Yr}$} \\
\hline Dec & June & Dec & June & Dec & June \\
\hline 4.45 & 5.30 & 5.43 & 5.43 & 5.24 & 6.11 \\
\hline
\end{tabular}
performance has not been as consistent as I'd like.

I recommend him highly for future management positions.

Human Resource Note: This supervisor has been accused by other supervisors of rating all of her direct reports too highly. However, while the evaluations of her subordinates are, in fact, higher, HR cannot rule out the possibility that her subordinates are actually better performers. There have also been many reports of arbitrary evaluation ratings but these are unsubstantiated at this time.

\section{ID No.: 3545 (Terry)}

Department: Investment Analysis

Division: $\quad$ Finance $\quad$ Education: B.S. Mathematics

Years Service: $\quad 3$

Supervisor: $\quad 054$ (Jennifer)

Univ of Connecticut

Supervisor's Summary:

I have had the pleasure of working closely with

Terry over the past three years. Her performance, while excellent, varies. Sometimes her work is truly outstanding; at other times merely above average. I would strongly recommend Terry for future management positions.

\begin{tabular}{|c|c|c|c|c|c|}
\hline \multicolumn{5}{|c|}{ Performance Evaluation Ratings } \\
\hline \multicolumn{2}{|c|}{$1^{\text {st }} \mathrm{Yr}$} & \multicolumn{2}{|c|}{$2^{\text {rd }} \mathrm{Yr}$} & \multicolumn{2}{c|}{$3^{\text {rd }}$} \\
\hline Dec & June & Dec & June & Dec & June \\
\hline 6.05 & 7.05 & 6.35 & 6.07 & 6.01 & 6.42 \\
\hline
\end{tabular}

Human Resource Note: This supervisor has been accused by other supervisors of rating all of her direct reports too highly. However, while the evaluations of her subordinates are, in fact, higher, HR cannot rule out the possibility that her subordinates are actually better performers. There have also been many reports of arbitrary evaluation ratings but these are unsubstantiated at this time.

\section{ID No.: 3546 (Neil)}

Department: Investment Analysis

Division: Finance $\quad$ Education: B.A. Business Admin.

Years Service: $3 \quad$ Eastern Conn State Univ

Supervisor: $\quad 038$ (Mark) 
Supervisor's Summary:

Neil has been a good solid performer from the get-go. Although he did not have a background in finance, I knew from the start that he had the skills for the analyst position. I'm particularly

\begin{tabular}{|c|c|c|c|c|c|}
\hline \multicolumn{6}{|c|}{ Performance Evaluation Ratings } \\
\hline \multicolumn{2}{|c|}{$1^{\text {st }} \mathrm{Yr}$} & \multicolumn{2}{c|}{$2^{\text {nd }} \mathrm{Yr}$} & \multicolumn{2}{c|}{$3^{\text {rd }} \mathrm{Yr}$} \\
\hline Dec & June & Dec & June & Dec & June \\
\hline 4.58 & 4.55 & 4.24 & 4.36 & 4.75 & 5.07 \\
\hline
\end{tabular}
impressed by Neil's integrity and commitment to the job.

Human Resource Note: There are several complaints in the supervisor's file regarding gender discrimination. None have been sufficiently documented to warrant official action.

\section{Group 2}

\section{ID No.: 3542 (Mary)}

$\begin{array}{ll}\text { Department: } & \text { Investment Analysis } \\ \text { Division: } & \text { Finance } \\ \text { Years Service: } & 3 \\ \text { Supervisor: } & 038 \text { (Mark) }\end{array}$

Education: $\quad$ MBA

Harvard

B.S. Yale, mathematics

Supervisor's Summary:

At the outset it was clear to me that Mary did not have the skills required for the position. This was surprising given her degree in mathematics although I understand her interest lay in typology

\begin{tabular}{|c|c|c|c|c|c|}
\hline \multicolumn{6}{|c|}{ Performance Evaluation Ratings } \\
\hline \multicolumn{2}{|c|}{$1^{\text {st }} \mathrm{Yr}$} & \multicolumn{2}{c|}{$2^{\text {nd }} \mathrm{Yr}$} & \multicolumn{2}{c|}{$3^{\text {rd }} \mathrm{Yr}$} \\
\hline Dec & June & Dec & June & Dec & June \\
\hline 4.74 & 4.52 & 3.98 & 3.46 & 3.30 & 3.82 \\
\hline
\end{tabular}
and not analytics. This job requires an analytical mind and she doesn't have it. Beyond this, Mary performed consistently and was able to complete her projects. She did, however, take significant time off to attend to family matters. In a few instances, I feel this hindered our department's performance.

Human Resource Note: There are several complaints in the supervisor's file regarding gender discrimination. None have been sufficiently documented to warrant official action.

\section{ID No.: 3543 (Linda)}

Department: Investment Analysis

$\begin{array}{llll}\text { Division: } & \text { Finance } & \text { Education: } & \text { M.S. Finance } \\ \text { Years Service: } & 3 & & \text { Univ of Southern Calif } \\ \text { Supervisor: } & 019 \text { (Henry) } & \text { B.S. USC Finance }\end{array}$

Supervisor's Summary:

Linda does good work - not always outstanding.

I am concerned with her consistency. It is

difficult to predict her performance review-to-

review.

\begin{tabular}{|c|c|c|c|c|c|}
\hline \multicolumn{6}{|c|}{ Performance Evaluation Ratings } \\
\hline \multicolumn{2}{|c|}{$1^{\text {st }} \mathrm{Yr}$} & \multicolumn{2}{|c|}{$2^{\text {nd }} \mathrm{Yr}$} & \multicolumn{2}{c|}{$3^{\text {rd }} \mathrm{Yr}$} \\
\hline Dec & June & Dec & June & Dec & June \\
\hline 5.58 & 5.83 & 7.51 & 5.30 & 5.30 & 6.21 \\
\hline
\end{tabular}

Human Resource Note: This supervisor has had several complaints from subordinates regarding unfair evaluations. There is insufficient evidence, however, to warrant action.

\section{ID No.: 3544 (Peter)}

Department: Investment Analysis

Division: $\quad$ Finance $\quad$ Education: B.S. Accounting

Years Service: $\quad 3$

Supervisor: $\quad 054$ (Jennifer)

Univ of Massachusetts

Supervisor's Summary: 


\section{Pernicious Performance Appraisals}

Peter is an excellent analyst. Although I do not work with Peter directly I am told that his performance is consistently above average. I have noted a few projects where his above average

\begin{tabular}{|c|c|c|c|c|c|}
\hline \multicolumn{5}{|c|}{ Performance Evaluation Ratings } \\
\hline \multicolumn{2}{|c|}{$1^{\text {st }} \mathrm{Yr}$} & \multicolumn{2}{c|}{$2^{\text {nd }} \mathrm{Yr}$} & \multicolumn{2}{c|}{$3^{\text {rd }} \mathrm{Yr}$} \\
\hline Dec & June & Dec & June & Dec & June \\
\hline 5.2 & 5.41 & 5.12 & 5.44 & 5.58 & 5.15 \\
\hline
\end{tabular}
performance has not been as consistent as I'd like.

I recommend him highly for future management positions.

Human Resource Note: This supervisor has been accused by other supervisors of rating all of her direct reports too highly. However, while the evaluations of her subordinates are, in fact, higher, HR cannot rule out the possibility that her subordinates are actually better performers. There have also been many reports of arbitrary evaluation ratings but these are unsubstantiated at this time.

\section{ID No.: 3545 (Terry)}

Department: Investment Analysis

Division: $\quad$ Finance $\quad$ Education: B.S. Mathematics

Years Service: $3 \quad$ Univ of Connecticut

Supervisor: $\quad 054$ (Jennifer)

Supervisor's Summary:

I have had the pleasure of working closely with

Terry over the past three years. Her performance, while excellent, varies. Sometimes her work is truly outstanding; at other times merely above average. I would strongly recommend Terry for

\begin{tabular}{|c|c|c|c|c|c|}
\hline \multicolumn{6}{|c|}{ Performance Evaluation Ratings } \\
\hline \multicolumn{2}{|c|}{$1^{\text {st }} \mathrm{Yr}$} & \multicolumn{2}{c|}{$2^{\text {nd }} \mathrm{Yr}$} & \multicolumn{2}{c|}{$3^{\text {rd }} \mathrm{Yr}$} \\
\hline Dec & June & Dec & June & Dec & June \\
\hline 4.77 & 4.90 & 6.83 & 5.68 & 4.50 & 5.12 \\
\hline
\end{tabular}
future management positions.

Human Resource Note: This supervisor has been accused by other supervisors of rating all of her direct reports too highly. However, while the evaluations of her subordinates are, in fact, higher, HR cannot rule out the possibility that her subordinates are actually better performers. There have also been many reports of arbitrary evaluation ratings but these are unsubstantiated at this time.

\section{ID No.: 3546 (Neil)}

Department: $\quad$ Investment Analysis

Division: Finance Education: B.A. Business Admin.

Years Service: $\quad 3 \quad$ Eastern Conn State Univ

Supervisor: $\quad 038$ (Mark)

Supervisor's Summary:

Neil has been a good solid performer from the get-go. Although he did not have a background in finance, I knew from the start that he had the skills for the analyst position. I'm particularly impressed by Neil's integrity and commitment to

\begin{tabular}{|c|c|c|c|c|c|}
\hline \multicolumn{6}{|c|}{ Performance Evaluation Ratings } \\
\hline \multicolumn{2}{|c|}{$1^{\text {st }} \mathrm{Yr}$} & \multicolumn{2}{c|}{$2^{\text {nd }} \mathrm{Yr}$} & \multicolumn{2}{c|}{$3^{\text {rd }} \mathrm{Yr}$} \\
\hline Dec & June & Dec & June & Dec & June \\
\hline 4.69 & 3.99 & 5.09 & 3.86 & 4.64 & 4.94 \\
\hline
\end{tabular}
the job.

Human Resource Note: There are several complaints in the supervisor's file regarding gender discrimination. None have been sufficiently documented to warrant official action.

\section{Group 3}

\section{ID No.: 3542 (Mary)}

Department: Investment Analysis

Division: Finance $\quad$ Education: MBA

Years Service: $\quad 3 \quad$ Harvard

$\begin{array}{lll}\text { Supervisor: } & 038 \text { (Mark) } \quad \text { B.S. Yale, mathematics }\end{array}$ 


\section{Pernicious Performance Appraisals}

Supervisor's Summary:

At the outset it was clear to me that Mary did not have the skills required for the position. This was surprising given her degree in mathematics although I understand her interest lay in typology

\begin{tabular}{|c|c|c|c|c|c|}
\hline \multicolumn{6}{|c|}{ Performance Evaluation Ratings } \\
\hline \multicolumn{2}{|c|}{$1^{\text {st }} \mathrm{Yr}$} & \multicolumn{2}{c|}{$2^{\text {nd }}$ Yr } & \multicolumn{2}{c|}{$3^{\text {rd }} \mathrm{Yr}$} \\
\hline Dec & June & Dec & June & Dec & June \\
\hline 4.27 & 3.12 & 3.35 & 3.87 & 2.80 & 3.33 \\
\hline
\end{tabular}

and not analytics. This job requires an analytical mind and she doesn't have it. Beyond this, Mary performed consistently and was able to complete her projects. She did, however, take significant time off to attend to family matters. In a few instances, I feel this hindered our department's performance.

Human Resource Note: There are several complaints in the supervisor's file regarding gender discrimination. None have been sufficiently documented to warrant official action.

\section{ID No.: 3543 (Linda)}

Department: Investment Analysis

Division: $\quad$ Finance

Years Service: $\quad 3$

Supervisor: $\quad 019$ (Henry)
Education: M.S. Finance

Univ of Southern Calif

B.S. USC Finance

Supervisor's Summary:

Linda does good work - not always outstanding.

I am concerned with her consistency. It is

difficult to predict her performance review-to-

review.

\begin{tabular}{|c|c|c|c|c|c|}
\hline \multicolumn{6}{|c|}{ Performance Evaluation Ratings } \\
\hline \multicolumn{2}{|c|}{$1^{\text {st }} \mathrm{Yr}$} & \multicolumn{2}{|c|}{$2^{\text {nd }} \mathrm{Yr}$} & \multicolumn{2}{c|}{$3^{\text {rd }} \mathrm{Yr}$} \\
\hline Dec & June & Dec & June & Dec & June \\
\hline 5.48 & 5.38 & 3.95 & 3.65 & 3.67 & 3.57 \\
\hline
\end{tabular}

Human Resource Note: This supervisor has had several complaints from subordinates regarding unfair evaluations. There is insufficient evidence, however, to warrant action.

\section{ID No.: 3544 (Peter)}

Department: $\quad$ Investment Analysis

$\begin{array}{llll}\text { Division: } & \text { Finance } & \text { Education: } & \text { B.S. Accounting } \\ \text { Years Service: } & 3 & & \text { Univ of Massachusetts } \\ \text { Supervisor: } & 054 \text { (Jennifer) } & & \end{array}$

Supervisor: $\quad 054$ (Jennifer)

Supervisor's Summary:

Peter is an excellent analyst. Although I do not work with Peter directly I am told that his performance is consistently above average. I have noted a few projects where his above average

\begin{tabular}{|c|c|c|c|c|c|}
\hline \multicolumn{5}{|c|}{ Performance Evaluation Ratings } \\
\hline \multicolumn{2}{|c|}{$1^{\text {st }} \mathrm{Yr}$} & \multicolumn{2}{|c|}{$2^{\text {nd }} \mathrm{Yr}$} & \multicolumn{2}{c|}{$3^{\text {rd }} \mathrm{Yr}$} \\
\hline Dec & June & Dec & June & Dec & June \\
\hline 5.18 & 4.42 & 5.67 & 5.72 & 5.91 & 6.63 \\
\hline
\end{tabular}
performance has not been as consistent as I'd like. I recommend him highly for future management positions.

Human Resource Note: This supervisor has been accused by other supervisors of rating all of her direct reports too highly. However, while the evaluations of her subordinates are, in fact, higher, HR cannot rule out the possibility that her subordinates are actually better performers. There have also been many reports of arbitrary evaluation ratings but these are unsubstantiated at this time.

\section{ID No.: 3545 (Terry)}

Department: $\quad$ Investment Analysis

$\begin{array}{llll}\text { Division: } & \text { Finance } & \text { Education: } & \text { B.S. Mathematics } \\ \text { Years Service: } & 3 & & \text { Univ of Connecticut } \\ \text { Supervisor: } & 054 \text { (Jennifer) } & \end{array}$

Supervisor's Summary:

Copyright (c) 2013 Institute of Behavioral and Ap

\begin{tabular}{|c|c|c|c|c|c|}
\hline \multicolumn{6}{|c|}{ Performance Evaluation Ratings } \\
\hline \multicolumn{2}{|c|}{$1^{\text {st }} \mathrm{Yr}$} & \multicolumn{2}{|c|}{$2^{\text {nd }} \mathrm{Yr}$} & \multicolumn{2}{c|}{$3^{\text {rd }} \mathrm{Yr}$} \\
\hline Dec & June & Dec & June & Dec & June \\
\hline 5.80 & 5.82 & 6.52 & 6.81 & 6.32 & 7.32 \\
\hline
\end{tabular}




\section{Pernicious Performance Appraisals}

I have had the pleasure of working closely with Terry over the past three years. Her performance, while excellent, varies. Sometimes her work is truly outstanding; at other times merely above average. I would strongly recommend Terry for future management positions.

Human Resource Note: This supervisor has been accused by other supervisors of rating all of her direct reports too highly. However, while the evaluations of her subordinates are, in fact, higher, HR cannot rule out the possibility that her subordinates are actually better performers. There have also been many reports of arbitrary evaluation ratings but these are unsubstantiated at this time.

ID No.: 3546 (Neil)

Department: Investment Analysis

Division: Finance Education: B.A. Business Admin.

Years Service: $\quad 3 \quad$ Eastern Conn State Univ

Supervisor: $\quad 038$ (Mark)

Supervisor's Summary:

Neil has been a good solid performer from the get-go. Although he did not have a background in finance, I knew from the start that he had the skills for the analyst position. I'm particularly impressed by Neil's integrity and commitment to

\begin{tabular}{|c|c|c|c|c|c|}
\hline \multicolumn{6}{|c|}{ Performance Evaluation Ratings } \\
\hline \multicolumn{2}{|c|}{$1^{\text {sl }}$ Yr } & \multicolumn{2}{|c|}{$2^{\text {nd }}$ Yr } & \multicolumn{2}{c|}{$3^{\text {rd }} \mathrm{Yr}$} \\
\hline Dec & June & Dec & June & Dec & June \\
\hline 4.67 & 4.56 & 5.26 & 4.40 & 5.07 & 5.09 \\
\hline
\end{tabular}
the job.

Human Resource Note: There are several complaints in the supervisor's file regarding gender discrimination. None have been sufficiently documented to warrant official action.

\section{Group 4}

\section{ID No.: 3542 (Mary)}

Department: $\quad$ Investment Analysis

Division: $\quad$ Finance $\quad$ Education: MBA

Years Service: $\quad 3 \quad$ Harvard

$\begin{array}{lll}\text { Supervisor: } & 038 \text { (Mark) } & \text { B.S. Yale, mathematics }\end{array}$

Supervisor's Summary:

At the outset it was clear to me that Mary did not have the skills required for the position. This was surprising given her degree in mathematics although I understand her interest lay in typology

\begin{tabular}{|c|c|c|c|c|c|}
\hline \multicolumn{6}{|c|}{ Performance Evaluation Ratings } \\
\hline \multicolumn{2}{|c|}{$1^{\text {st }} \mathrm{Yr}$} & \multicolumn{2}{c|}{$2^{\text {nd }} \mathrm{Yr}$} & \multicolumn{2}{c|}{$3^{\text {rd }} \mathrm{Yr}$} \\
\hline Dec & June & Dec & June & Dec & June \\
\hline 4.23 & 3.35 & 3.68 & 3.38 & 3.32 & 2.40 \\
\hline
\end{tabular}
and not analytics. This job requires an analytical mind and she doesn't have it. Beyond this, Mary performed consistently and was able to complete her projects. She did, however, take significant time off to attend to family matters. In a few instances, I feel this hindered our department's performance.

Human Resource Note: There are several complaints in the supervisor's file regarding gender discrimination. None have been sufficiently documented to warrant official action.

\section{ID No.: 3543 (Linda)}

Department: Investment Analysis

Division: $\quad$ Finance $\quad$ Education: M.S. Finance

Years Service: $3 \quad$ Univ of Southern Calif

Supervisor: 019 (Henry) B.S. USC Finance

Supervisor's Summary:

Copyright (c) 2013 Institute of Behavioral and Ap]

\begin{tabular}{|c|c|c|c|c|c|}
\hline \multicolumn{6}{|c|}{ Performance Evaluation Ratings } \\
\hline \multicolumn{2}{|c|}{$1^{\text {st }} \mathrm{Yr}$} & \multicolumn{2}{|c|}{$2^{\text {nd }} \mathrm{Yr}$} & \multicolumn{2}{c|}{$3^{\text {rd }} \mathrm{Yr}$} \\
\hline Dec & June & Dec & June & Dec & June \\
\hline 5.53 & 6.85 & 5.13 & 3.64 & 5.03 & 6.26 \\
\hline
\end{tabular}




\section{Pernicious Performance Appraisals}

Linda does good work - not always outstanding. I am concerned with her consistency. It is difficult to predict her performance review-to-review.

Human Resource Note: This supervisor has had several complaints from subordinates regarding unfair evaluations. There is insufficient evidence, however, to warrant action.

\section{ID No.: 3544 (Peter)}

Department: Investment Analysis

Division: $\quad$ Finance $\quad$ Education: B.S. Accounting Years Service: $3 \quad$ Univ of Massachusetts

Supervisor: $\quad 054$ (Jennifer)

Supervisor's Summary:

Peter is an excellent analyst. Although I do not work with Peter directly I am told that his performance is consistently above average. I have noted a few projects where his above average performance has not been as consistent as I'd like.

I recommend him highly for future management positions.

Human Resource Note: This supervisor has been accused by other supervisors of rating all of her direct reports too highly. However, while the evaluations of her subordinates are, in fact, higher, HR cannot rule out the possibility that her subordinates are actually better performers. There have also been many reports of arbitrary evaluation ratings but these are unsubstantiated at this time.

\section{ID No.: 3545 (Terry)}

Department: Investment Analysis

Division: Finance Education: B.S. Mathematics

Years Service: $3 \quad$ Univ of Connecticut

Supervisor: $\quad 054$ (Jennifer)

Supervisor's Summary:

I have had the pleasure of working closely with

Terry over the past three years. Her performance, while excellent, varies. Sometimes her work is truly outstanding; at other times merely above average. I would strongly recommend Terry for future management positions.

\begin{tabular}{|c|c|c|c|c|c|}
\hline \multicolumn{5}{|c|}{ Performance Evaluation Ratings } \\
\hline \multicolumn{2}{|c|}{$1^{\text {st }} \mathrm{Yr}$} & \multicolumn{2}{|c|}{$2^{\text {nd }} \mathrm{Yr}$} & \multicolumn{2}{c|}{$3^{\text {rd }} \mathrm{Yr}$} \\
\hline Dec & June & Dec & June & Dec & June \\
\hline 5.92 & 5.45 & 6.41 & 5.85 & 3.80 & 6.75 \\
\hline
\end{tabular}

Human Resource Note: This supervisor has been accused by other supervisors of rating all of her direct reports too highly. However, while the evaluations of her subordinates are, in fact, higher, HR cannot rule out the possibility that her subordinates are actually better performers. There have also been many reports of arbitrary evaluation ratings but these are unsubstantiated at this time.

\section{ID No.: 3546 (Neil)}

Department: $\quad$ Investment Analysis

Division: Finance $\quad$ Education: B.A. Business Admin.

Years Service: $\quad 3 \quad$ Eastern Conn State Univ

Supervisor: $\quad 038$ (Mark)

Supervisor's Summary:

Neil has been a good solid performer from the get-go. Although he did not have a background in finance, I knew from the start that he had the skills for the analyst position. I'm particularly

\begin{tabular}{|c|c|c|c|c|c|}
\hline \multicolumn{5}{|c|}{ Performance Evaluation Ratings } \\
\hline \multicolumn{2}{|c|}{$1^{\text {st }} \mathrm{Yr}$} & \multicolumn{2}{|c|}{$2^{\text {nd }} \mathrm{Yr}$} & \multicolumn{2}{c|}{$3^{\text {rd }} \mathrm{Yr}$} \\
\hline Dec & June & Dec & June & Dec & June \\
\hline 5.39 & 5.81 & 5.56 & 5.40 & 6.65 & 6.05 \\
\hline
\end{tabular}




\section{Pernicious Performance Appraisals}

impressed by Neil's integrity and commitment to the job.

Human Resource Note: There are several complaints in the supervisor's file regarding gender discrimination. None have been sufficiently documented to warrant official action.

\section{Analyst Scripts (Provided to the analysts)}

\section{Group 1}

Employee ID No. : 3542 MARY

You were hired 3 years ago to be a financial analyst for xyz corp. When you were hired, it was made very clear that four other analysts were hired with the intention to let one of you go after 3 years. This is a competitive company and it wants only the best people. They have zero tolerance for poor performance.

It is now time for the company to make the decision as to who gets fired. You also find out that one of your cohort will be selected for promotion to a supervisory position; this comes with a $20 \%$ raise and a $\$ 10,000$ bonus.

You are nervous about the upcoming decision. You have the distinct impression that your boss doesn't like you - you didn't hit it off right at the start. Since then, he has made snide comments from time-to-time that insinuating that

\begin{tabular}{|c|c|c|c|c|c|}
\hline \multicolumn{6}{|c|}{ Performance Evaluation Ratings } \\
\hline \multicolumn{2}{|c|}{$1^{\text {st }} \mathrm{Yr}$} & \multicolumn{2}{c|}{$2^{\text {nd }} \mathrm{Yr}$} & \multicolumn{2}{c|}{$3^{\text {rd }} \mathrm{Yr}$} \\
\hline Dec & June & Dec & June & Dec & June \\
\hline 4.57 & 3.21 & 4.34 & 3.97 & 3.58 & 3.57 \\
\hline
\end{tabular}
you can't do your job. You know very well that you can do the job as well or better than the other analysts. You also think your boss prefers the men in the department - he jokes around more with them. The trouble is that you have nothing to prove your gut feelings. You are afraid to even the raise the issue without documentation for fear of being labeled a 'feminist' or complainer. You wish you could start over with your boss and make a better first impression.

What has not helped your relationship with your boss is that you have two children in grade school and no husband to help out - you divorced when you were getting your MBA from Harvard. There have been many instances where you have had to request time off during the day. You boss has been seemingly understanding but it is clear that he is allowing it more because the company's policy is to be accommodating than because he believes in it. You have made it very evident that anytime lost has been more than made up for by staying late other days. Still you believe that this has played a role in your evaluation ratings. You're not sure but you could be the one being let go.

Supervisor: 038 (Mark)

Coworker: Neil

Employee ID No. : 3543 LINDA

You were hired 3 years ago to be a financial analyst for xyz corp. When you were hired, it was made very clear that four other analysts were hired with the intention to let one of you go after 3 years. This is a competitive company and it wants only the best people. They have zero tolerance for poor performance.

It is now time for the company to make the decision as to who gets fired. You also find out that one of your cohort will be selected for promotion to a supervisory position; this comes with a $20 \%$ raise and a $\$ 10,000$ bonus.

You have the impression that your boss likes you. In fact, you have noticed that he seems to go out of his way to help you - more so than with the men in the department. It is not overt, but

\begin{tabular}{|c|c|c|c|c|c|}
\hline \multicolumn{5}{|c|}{ Performance Evaluation Ratings } \\
\hline \multicolumn{2}{|c|}{$1^{\text {st }} \mathrm{Yr}$} & \multicolumn{2}{|c|}{$2^{\text {na }} \mathrm{Yr}$} & \multicolumn{2}{c|}{$3^{\text {rd }} \mathrm{Yr}$} \\
\hline Dec & June & Dec & June & Dec & June \\
\hline 5.08 & 3.92 & 4.33 & 5.22 & 5.02 & 6.85 \\
\hline
\end{tabular}
something you feel. The trouble with him, however, is that he is really inconsistent. You never know if he'll give you a slight reprimand (criticism) or if he'll come by and give you a pat-on-the-back. It is unnerving. You know that part of the changes in the performance evaluation is related to how he was feeling that day. You try to judge his 'good' days before asking for things.

One of the things you have to ask for - more often than you'd like - is for time during the day to deal with your grade schoolers. You are constantly having to run to the school and pick them up or have to leave early because 


\section{Pernicious Performance Appraisals}

to pick them up. Your husband travels so he can't do this. But at least your boss seems to understand. Still you feel you have a good shot at the promotion.

Supervisor: 019 (Henry)

Coworker: None

Employee ID No. : 3544 PETER

You were hired 3 years ago to be a financial analyst for xyz corp. When you were hired, it was made very clear that four other analysts were hired with the intention to let one of you go after 3 years. This is a competitive company and it wants only the best people. They have zero tolerance for poor performance.

It is now time for the company to make the decision as to who gets fired. You also find out that one of your cohort will be selected for promotion to a supervisory position; this comes with a $20 \%$ raise and a $\$ 10,000$ bonus.

You are nervous about the upcoming decision. You don't work in the same building as your boss and you think that has hurt you - she doesn't know you really. You have no complaints

\begin{tabular}{|c|c|c|c|c|c|}
\hline \multicolumn{5}{|c|}{ Performance Evaluation Ratings } \\
\hline \multicolumn{2}{|c|}{$1^{\text {st }} \mathrm{Yr}$} & \multicolumn{2}{c|}{$2^{\text {nd }} \mathrm{Yr}$} & \multicolumn{2}{c|}{$3^{\text {rd }} \mathrm{Yr}$} \\
\hline Dec & June & Dec & June & Dec & June \\
\hline 4.45 & 5.30 & 5.43 & 5.43 & 5.24 & 6.11 \\
\hline
\end{tabular}
with your performance evaluations - she seems fair and has been very consistent with how she approaches the evaluation. The trouble is that she doesn't seem to cut you a break when there are reasons for problems that come up. Maybe that's because she isn't here to see what is going on. But, she has been pretty supportive otherwise of you over the three years. You really have no complaints except for not working directly with her. That bothers you.

You are married but do not have children. You resent it when other analysts get time off to deal with their kids. You don't have to request that time. You don't think your boss takes that into account. Overall, you feel you have a shot at the promotion.

Supervisor: 054 (Jennifer)

Coworker: Terry

\section{Employee ID No. : 3545 TERRY}

You were hired 3 years ago to be a financial analyst for xyz corp. When you were hired, it was made very clear that four other analysts were hired with the intention to let one of you go after 3 years. This is a competitive company and it wants only the best people. They have zero tolerance for poor performance.

It is now time for the company to make the decision as to who gets fired. You also find out that one of your cohort will be selected for promotion to a supervisory position; this comes with a $20 \%$ raise and a $\$ 10,000$ bonus.

You and your boss get along very well. She has been very supportive of you over the years. But she's not treating you differently - she is supportive of her entire staff. Your only complaint, and it's minor, is that she doesn't

\begin{tabular}{|c|c|c|c|c|c|}
\hline \multicolumn{6}{|c|}{ Performance Evaluation Ratings } \\
\hline \multicolumn{2}{|c|}{$1^{\text {st }} \mathrm{Yr}$} & \multicolumn{2}{c|}{$2^{\text {nd }} \mathrm{Yr}$} & \multicolumn{2}{c|}{$3^{\text {rd }} \mathrm{Yr}$} \\
\hline Dec & June & Dec & June & Dec & June \\
\hline 6.05 & 7.05 & 6.35 & 6.07 & 6.01 & 6.42 \\
\hline
\end{tabular}
always appreciate that you can't always control your performance. If a project goes sour she tends to blame you and you don't think that's fair. But this is really minor. You can't complain.

In fact, the few times you've needed time off during the day to pick up your kid at school, she has been very understanding. She didn't even ask that you make up the time. Yes, you're sitting in a good position. You may even get that promotion.

Supervisor: 054 (Jennifer)

Coworker: Peter

Employee ID No. : 3546 NEIL

You were hired 3 years ago to be a financial analyst for xyz corp. When you were hired, it was made very clear that four other analysts were hired with the intention to let one of you go after 3 years. This is a competitive company and it wants only the best people. They have zero tolerance for poor performance. 


\section{Pernicious Performance ApPraisals}

It is now time for the company to make the decision as to who gets fired. You also find out that one of your cohort will be selected for promotion to a supervisory position; this comes with a $20 \%$ raise and a $\$ 10,000$ bonus.

Your boss seems the type to make up his mind quickly and stick to it. You and he hit it off on the first day and you've gotten along ever since. He has been very supportive and understanding

\begin{tabular}{|c|c|c|c|c|c|}
\hline \multicolumn{6}{|c|}{ Performance Evaluation Ratings } \\
\hline \multicolumn{2}{|c|}{$1^{\text {st }} \mathrm{Yr}$} & \multicolumn{2}{c|}{$2^{\text {nd }} \mathrm{Yr}$} & \multicolumn{2}{c|}{$3^{\text {rd }} \mathrm{Yr}$} \\
\hline Dec & June & Dec & June & Dec & June \\
\hline 4.58 & 4.55 & 4.24 & 4.36 & 4.75 & 5.07 \\
\hline
\end{tabular}
over the three years. You have not always succeeded in your projects but your boss has actually pointed out reasons for the failure that were outside your control. Now that's impressive! You consider him a fair and excellent supervisor. You think you have a shot at that promotion. Your only concern is that, as a bachelor, you've had some rough mornings after a night out.

Supervisor: 038 (Mark)

Coworker: Mary

\section{Group 2}

\section{Employee ID No. : 3542 MARY}

You were hired 3 years ago to be a financial analyst for xyz corp. When you were hired, it was made very clear that four other analysts were hired with the intention to let one of you go after 3 years. This is a competitive company and it wants only the best people. They have zero tolerance for poor performance.

It is now time for the company to make the decision as to who gets fired. You also find out that one of your cohort will be selected for promotion to a supervisory position; this comes with a $20 \%$ raise and a $\$ 10,000$ bonus.

You are nervous about the upcoming decision. You have the distinct impression that your boss doesn't like you - you didn't hit it off right at the start. Since then, he has made snide comments from time-to-time that insinuating that

\begin{tabular}{|c|c|c|c|c|c|}
\hline \multicolumn{6}{|c|}{ Performance Evaluation Ratings } \\
\hline \multicolumn{2}{|c|}{$1^{\text {st }} \mathrm{Yr}$} & \multicolumn{2}{c|}{$2^{\text {nd }} \mathrm{Yr}$} & \multicolumn{2}{c|}{$3^{\text {rd }} \mathrm{Yr}$} \\
\hline Dec & June & Dec & June & Dec & June \\
\hline 4.74 & 4.52 & 3.98 & 3.46 & 3.30 & 3.82 \\
\hline
\end{tabular}
you can't do your job. You know very well that you can do the job as well or better than the other analysts. You also think your boss prefers the men in the department - he jokes around more with them. The trouble is that you have nothing to prove your gut feelings. You are afraid to even the raise the issue without documentation for fear of being labeled a 'feminist' or complainer. You wish you could start over with your boss and make a better first impression.

What has not helped your relationship with your boss is that you have two children in grade school and no husband to help out - you divorced when you were getting your MBA from Harvard. There have been many instances where you have had to request time off during the day. You boss has been seemingly understanding but it is clear that he is allowing it more because the company's policy is to be accommodating than because he believes in it. You have made it very evident that anytime lost has been more than made up for by staying late other days. Still you believe that this has played a role in your evaluation ratings. You're not sure but you could be the one being let go.

Supervisor: 038 (Mark)

Coworker: Neil

Employee ID No. : 3543 LINDA

You were hired 3 years ago to be a financial analyst for xyz corp. When you were hired, it was made very clear that four other analysts were hired with the intention to let one of you go after 3 years. This is a competitive company and it wants only the best people. They have zero tolerance for poor performance.

It is now time for the company to make the decision as to who gets fired. You also find out that one of your cohort will be selected for promotion to a supervisory position; this comes with a $20 \%$ raise and a $\$ 10,000$ bonus.

You have the impression that your boss likes you. In fact, you have noticed that he seems to go out of his way to help you - more so than with

\begin{tabular}{|c|c|c|c|c|c|}
\hline \multicolumn{5}{|c|}{ Performance Evaluation Ratings } \\
\hline \multicolumn{2}{|c|}{$1^{\text {st }} \mathrm{Yr}$} & \multicolumn{2}{c|}{$2^{\text {nd }} \mathrm{Yr}$} & \multicolumn{2}{c|}{$3^{\text {rd }} \mathrm{Yr}$} \\
\hline Dec & June & Dec & June & Dec & June \\
\hline 5.58 & 5.83 & 7.51 & 5.30 & 5.30 & 6.21 \\
\hline
\end{tabular}




\section{Pernicious Performance Appraisals}

the men in the department. It is not overt, but something you feel. The trouble with him, however, is that he is really inconsistent. You never know if he'll give you a slight reprimand (criticism) or if he'll come by and give you a paton-the-back. It is unnerving. You know that part of the changes in the performance evaluation is related to how he was feeling that day. You try to judge his 'good' days before asking for things.

One of the things you have to ask for - more often than you'd like - is for time during the day to deal with your grade schoolers. You are constantly having to run to the school and pick them up or have to leave early because to pick them up. Your husband travels so he can't do this. But at least your boss seems to understand. Still you feel you have a good shot at the promotion.

Supervisor: 019 (Henry)

Coworker: None

Employee ID No. : 3544 PETER

You were hired 3 years ago to be a financial analyst for xyz corp. When you were hired, it was made very clear that four other analysts were hired with the intention to let one of you go after 3 years. This is a competitive company and it wants only the best people. They have zero tolerance for poor performance.

It is now time for the company to make the decision as to who gets fired. You also find out that one of your cohort will be selected for promotion to a supervisory position; this comes with a $20 \%$ raise and a $\$ 10,000$ bonus.

You are nervous about the upcoming decision. You don't work in the same building as your boss and you think that has hurt you - she doesn't know you really. You have no complaints with your performance evaluations - she seems

\begin{tabular}{|c|c|c|c|c|c|}
\hline \multicolumn{5}{|c|}{ Performance Evaluation Ratings } \\
\hline \multicolumn{2}{|c|}{$1^{\text {st }} \mathrm{Yr}$} & \multicolumn{2}{|c|}{$2^{\text {nd }} \mathrm{Yr}$} & \multicolumn{2}{c|}{$3^{\text {rd }} \mathrm{Yr}$} \\
\hline Dec & June & Dec & June & Dec & June \\
\hline 5.2 & 5.41 & 5.12 & 5.44 & 5.58 & 5.15 \\
\hline
\end{tabular}
fair and has been very consistent with how she approaches the evaluation. The trouble is that she doesn't seem to cut you a break when there are reasons for problems that come up. Maybe that's because she isn't here to see what is going on. But, she has been pretty supportive otherwise of you over the three years. You really have no complaints except for not working directly with her. That bothers you.

You are married but do not have children. You resent it when other analysts get time off to deal with their kids. You don't have to request that time. You don't think your boss takes that into account. Overall, you feel you have a shot at the promotion.

Supervisor: 054 (Jennifer)

Coworker: Terry

\section{Employee ID No. : 3545 TERRY}

You were hired 3 years ago to be a financial analyst for xyz corp. When you were hired, it was made very clear that four other analysts were hired with the intention to let one of you go after 3 years. This is a competitive company and it wants only the best people. They have zero tolerance for poor performance.

It is now time for the company to make the decision as to who gets fired. You also find out that one of your cohort will be selected for promotion to a supervisory position; this comes with a $20 \%$ raise and a $\$ 10,000$ bonus.

You and your boss get along very well. She has been very supportive of you over the years. But she's not treating you differently - she is supportive of her entire staff. Your only complaint, and it's minor, is that she doesn't

\begin{tabular}{|c|c|c|c|c|c|}
\hline \multicolumn{6}{|c|}{ Performance Evaluation Ratings } \\
\hline \multicolumn{2}{|c|}{$1^{\text {st }} \mathrm{Yr}$} & \multicolumn{2}{c|}{$2^{\text {nd }} \mathrm{Yr}$} & \multicolumn{2}{c|}{$3^{\text {rd }} \mathrm{Yr}$} \\
\hline Dec & June & Dec & June & Dec & June \\
\hline 4.77 & 4.90 & 6.83 & 5.68 & 4.50 & 5.12 \\
\hline
\end{tabular}
always appreciate that you can't always control your performance. If a project goes sour she tends to blame you and you don't think that's fair. But this is really minor. You can't complain.

In fact, the few times you've needed time off during the day to pick up your kid at school, she has been very understanding. She didn't even ask that you make up the time. Yes, you're sitting in a good position. You may even get that promotion.

Supervisor: 054 (Jennifer) 


\section{Pernicious Performance Appraisals}

Coworker: Peter

Employee ID No. : 3546 NEIL

You were hired 3 years ago to be a financial analyst for xyz corp. When you were hired, it was made very clear that four other analysts were hired with the intention to let one of you go after 3 years. This is a competitive company and it wants only the best people. They have zero tolerance for poor performance.

It is now time for the company to make the decision as to who gets fired. You also find out that one of your cohort will be selected for promotion to a supervisory position; this comes with a $20 \%$ raise and a $\$ 10,000$ bonus.

Your boss seems the type to make up his mind quickly and stick to it. You and he hit it off on the first day and you've gotten along ever since. He has been very supportive and understanding over the three years. You have not always succeeded in your projects but your boss has actually pointed out reasons for the failure that were outside your control. Now that's impressive! You consider him a fair and excellent supervisor. You think you have a shot at that promotion. Your only concern is that, as a bachelor, you've had some rough mornings after a night out.

Supervisor: 038 (Mark)

Coworker: Mary

\section{Group 3}

Employee ID No. : 3542 MARY

You were hired 3 years ago to be a financial analyst for xyz corp. When you were hired, it was made very clear that four other analysts were hired with the intention to let one of you go after 3 years. This is a competitive company and it wants only the best people. They have zero tolerance for poor performance.

It is now time for the company to make the decision as to who gets fired. You also find out that one of your cohort will be selected for promotion to a supervisory position; this comes with a $20 \%$ raise and a $\$ 10,000$ bonus.

You are nervous about the upcoming decision. You have the distinct impression that your boss doesn't like you - you didn't hit it off right at the start. Since then, he has made snide comments from time-to-time that insinuating that

\begin{tabular}{|c|c|c|c|c|c|}
\hline \multicolumn{6}{|c|}{ Performance Evaluation Ratings } \\
\hline \multicolumn{2}{|c|}{$1^{\text {st }} \mathrm{Yr}$} & \multicolumn{2}{|c|}{$2^{\text {nd }} \mathrm{Yr}$} & \multicolumn{2}{c|}{$3^{\text {rd }} \mathrm{Yr}$} \\
\hline Dec & June & Dec & June & Dec & June \\
\hline 4.27 & 3.12 & 3.35 & 3.87 & 2.80 & 3.33 \\
\hline
\end{tabular}
you can't do your job. You know very well that you can do the job as well or better than the other analysts. You also think your boss prefers the men in the department - he jokes around more with them. The trouble is that you have nothing to prove your gut feelings. You are afraid to even the raise the issue without documentation for fear of being labeled a 'feminist' or complainer. You wish you could start over with your boss and make a better first impression.

What has not helped your relationship with your boss is that you have two children in grade school and no husband to help out - you divorced when you were getting your MBA from Harvard. There have been many instances where you have had to request time off during the day. You boss has been seemingly understanding but it is clear that he is allowing it more because the company's policy is to be accommodating than because he believes in it. You have made it very evident that anytime lost has been more than made up for by staying late other days. Still you believe that this has played a role in your evaluation ratings. You're not sure but you could be the one being let go.

Supervisor: 038 (Mark)

Coworker: Neil

Employee ID No. : 3543 LINDA 


\section{Pernicious Performance Appraisals}

You were hired 3 years ago to be a financial analyst for xyz corp. When you were hired, it was made very clear that four other analysts were hired with the intention to let one of you go after 3 years. This is a competitive company and it wants only the best people. They have zero tolerance for poor performance.

It is now time for the company to make the decision as to who gets fired. You also find out that one of your cohort will be selected for promotion to a supervisory position; this comes with a $20 \%$ raise and a $\$ 10,000$ bonus.

You have the impression that your boss likes you. In fact, you have noticed that he seems to go out of his way to help you - more so than with the men in the department. It is not overt, but

\begin{tabular}{|c|c|c|c|c|c|}
\hline \multicolumn{5}{|c|}{ Performance Evaluation Ratings } \\
\hline \multicolumn{2}{|c|}{$1^{\text {st }} \mathrm{Yr}$} & \multicolumn{2}{|c|}{$2^{\text {nd }} \mathrm{Yr}$} & \multicolumn{2}{c|}{$3^{\text {rd }} \mathrm{Yr}$} \\
\hline Dec & June & Dec & June & Dec & June \\
\hline 5.48 & 5.38 & 3.95 & 3.65 & 3.67 & 3.57 \\
\hline
\end{tabular}
something you feel. The trouble with him, however, is that he is really inconsistent. You never know if he'll give you a slight reprimand (criticism) or if he'll come by and give you a pat-on-the-back. It is unnerving. You know that part of the changes in the performance evaluation is related to how he was feeling that day. You try to judge his 'good' days before asking for things.

One of the things you have to ask for - more often than you'd like - is for time during the day to deal with your grade schoolers. You are constantly having to run to the school and pick them up or have to leave early because to pick them up. Your husband travels so he can't do this. But at least your boss seems to understand. Still you feel you have a good shot at the promotion.

Supervisor: 019 (Henry)

Coworker: None

Employee ID No. : 3544 PETER

You were hired 3 years ago to be a financial analyst for xyz corp. When you were hired, it was made very clear that four other analysts were hired with the intention to let one of you go after 3 years. This is a competitive company and it wants only the best people. They have zero tolerance for poor performance.

It is now time for the company to make the decision as to who gets fired. You also find out that one of your cohort will be selected for promotion to a supervisory position; this comes with a $20 \%$ raise and a $\$ 10,000$ bonus.

You are nervous about the upcoming decision. You don't work in the same building as your boss and you think that has hurt you - she doesn't know you really. You have no complaints with your performance evaluations - she seems

\begin{tabular}{|c|c|c|c|c|c|}
\hline \multicolumn{5}{|c|}{ Performance Evaluation Ratings } \\
\hline \multicolumn{2}{|c|}{$1^{\text {st }} \mathrm{Yr}$} & \multicolumn{2}{|c|}{$2^{\text {nd }} \mathrm{Yr}$} & \multicolumn{2}{c|}{$3^{\text {rd }} \mathrm{Yr}$} \\
\hline Dec & June & Dec & June & Dec & June \\
\hline 5.18 & 4.42 & 5.67 & 5.72 & 5.91 & 6.63 \\
\hline
\end{tabular}
fair and has been very consistent with how she approaches the evaluation. The trouble is that she doesn't seem to cut you a break when there are reasons for problems that come up. Maybe that's because she isn't here to see what is going on. But, she has been pretty supportive otherwise of you over the three years. You really have no complaints except for not working directly with her. That bothers you.

You are married but do not have children. You resent it when other analysts get time off to deal with their kids. You don't have to request that time. You don't think your boss takes that into account. Overall, you feel you have a shot at the promotion.

Supervisor: 054 (Jennifer)

Coworker: Terry

Employee ID No. : 3545 TERRY

You were hired 3 years ago to be a financial analyst for xyz corp. When you were hired, it was made very clear that four other analysts were hired with the intention to let one of you go after 3 years. This is a competitive company and it wants only the best people. They have zero tolerance for poor performance.

It is now time for the company to make the decision as to who gets fired. You also find out that one of your cohort will be selected for promotion to a supervisory position; this comes with a $20 \%$ raise and a $\$ 10,000$ bonus. 


\section{Pernicious Performance Appraisals}

You and your boss get along very well. She has been very supportive of you over the years. But she's not treating you differently - she is supportive of her entire staff. Your only complaint, and it's minor, is that she doesn't

\begin{tabular}{|c|c|c|c|c|c|}
\hline \multicolumn{6}{|c|}{ Performance Evaluation Ratings } \\
\hline \multicolumn{2}{|c|}{$1^{\text {st }} \mathrm{Yr}$} & \multicolumn{2}{|c|}{$2^{\text {nd }} \mathrm{Yr}$} & \multicolumn{2}{c|}{$3^{\text {rd }} \mathrm{Yr}$} \\
\hline Dec & June & Dec & June & Dec & June \\
\hline 5.80 & 5.82 & 6.52 & 6.81 & 6.32 & 7.32 \\
\hline
\end{tabular}
always appreciate that you can't always control your performance. If a project goes sour she tends to blame you and you don't think that's fair. But this is really minor. You can't complain.

In fact, the few times you've needed time off during the day to pick up your kid at school, she has been very understanding. She didn't even ask that you make up the time. Yes, you're sitting in a good position. You may even get that promotion.

Supervisor: 054 (Jennifer)

Coworker: Peter

Employee ID No. : 3546 NEIL

You were hired 3 years ago to be a financial analyst for xyz corp. When you were hired, it was made very clear that four other analysts were hired with the intention to let one of you go after 3 years. This is a competitive company and it wants only the best people. They have zero tolerance for poor performance.

It is now time for the company to make the decision as to who gets fired. You also find out that one of your cohort will be selected for promotion to a supervisory position; this comes with a $20 \%$ raise and a $\$ 10,000$ bonus.

Your boss seems the type to make up his mind quickly and stick to it. You and he hit it off on the first day and you've gotten along ever since. He has been very supportive and understanding over the three years. You have not always succeeded in your projects but your boss has actually pointed out reasons for the failure that were outside your control. Now that's impressive! You consider him a fair and excellent supervisor. You think you have a shot at that promotion. Your only concern is that, as a bachelor, you've had some rough mornings after a night out.

Supervisor: 038 (Mark)

Coworker: Mary

\section{Group 4}

\section{Employee ID No. : 3542 MARY}

You were hired 3 years ago to be a financial analyst for xyz corp. When you were hired, it was made very clear that four other analysts were hired with the intention to let one of you go after 3 years. This is a competitive company and it wants only the best people. They have zero tolerance for poor performance.

It is now time for the company to make the decision as to who gets fired. You also find out that one of your cohort will be selected for promotion to a supervisory position; this comes with a $20 \%$ raise and a $\$ 10,000$ bonus.

You are nervous about the upcoming decision. You have the distinct impression that your boss doesn't like you - you didn't hit it off right at the start. Since then, he has made snide comments from time-to-time that insinuating that

\begin{tabular}{|c|c|c|c|c|c|}
\hline \multicolumn{5}{|c|}{ Performance Evaluation Ratings } \\
\hline \multicolumn{2}{|c|}{$1^{\text {st }} \mathrm{Yr}$} & \multicolumn{2}{|c|}{$2^{\text {nd }} \mathrm{Yr}$} & \multicolumn{2}{c|}{$3^{\text {rd }} \mathrm{Yr}$} \\
\hline Dec & June & Dec & June & Dec & June \\
\hline 4.23 & 3.35 & 3.68 & 3.38 & 3.32 & 2.40 \\
\hline
\end{tabular}
you can't do your job. You know very well that you can do the job as well or better than the other analysts. You also think your boss prefers the men in the department - he jokes around more with them. The trouble is that you have nothing to prove your gut feelings. You are afraid to even the raise the issue without documentation for fear of being labeled a 'feminist' or complainer. You wish you could start over with your boss and make a better first impression.

What has not helped your relationship with your boss is that you have two children in grade school and no husband to help out - you divorced when you were getting your MBA from Harvard. There have been many 


\section{Pernicious Performance Appraisals}

instances where you have had to request time off during the day. You boss has been seemingly understanding but it is clear that he is allowing it more because the company's policy is to be accommodating than because he believes in it. You have made it very evident that anytime lost has been more than made up for by staying late other days. Still you believe that this has played a role in your evaluation ratings. You're not sure but you could be the one being let go.

Supervisor: 038 (Mark)

Coworker: Neil

Employee ID No. : 3543 LINDA

You were hired 3 years ago to be a financial analyst for xyz corp. When you were hired, it was made very clear that four other analysts were hired with the intention to let one of you go after 3 years. This is a competitive company and it wants only the best people. They have zero tolerance for poor performance.

It is now time for the company to make the decision as to who gets fired. You also find out that one of your cohort will be selected for promotion to a supervisory position; this comes with a $20 \%$ raise and a $\$ 10,000$ bonus.

You have the impression that your boss likes you. In fact, you have noticed that he seems to go out of his way to help you - more so than with the men in the department. It is not overt, but

\begin{tabular}{|c|c|c|c|c|c|}
\hline \multicolumn{6}{|c|}{ Performance Evaluation Ratings } \\
\hline \multicolumn{2}{|c|}{$1^{\text {st }} \mathrm{Yr}$} & \multicolumn{2}{c|}{$2^{\text {nd }} \mathrm{Yr}$} & \multicolumn{2}{c|}{$3^{\text {rd }} \mathrm{Yr}$} \\
\hline Dec & June & Dec & June & Dec & June \\
\hline 5.53 & 6.85 & 5.13 & 3.64 & 5.03 & 6.26 \\
\hline
\end{tabular}
something you feel. The trouble with him, however, is that he is really inconsistent. You never know if he'll give you a slight reprimand (criticism) or if he'll come by and give you a pat-on-the-back. It is unnerving. You know that part of the changes in the performance evaluation is related to how he was feeling that day. You try to judge his 'good' days before asking for things.

One of the things you have to ask for - more often than you'd like - is for time during the day to deal with your grade schoolers. You are constantly having to run to the school and pick them up or have to leave early because to pick them up. Your husband travels so he can't do this. But at least your boss seems to understand. Still you feel you have a good shot at the promotion.

Supervisor: 019 (Henry)

Coworker: None

Employee ID No. : 3544 PETER

You were hired 3 years ago to be a financial analyst for xyz corp. When you were hired, it was made very clear that four other analysts were hired with the intention to let one of you go after 3 years. This is a competitive company and it wants only the best people. They have zero tolerance for poor performance.

It is now time for the company to make the decision as to who gets fired. You also find out that one of your cohort will be selected for promotion to a supervisory position; this comes with a $20 \%$ raise and a $\$ 10,000$ bonus.

You are nervous about the upcoming decision. You don't work in the same building as your boss and you think that has hurt you - she doesn't know you really. You have no complaints

\begin{tabular}{|c|c|c|c|c|c|}
\hline \multicolumn{6}{|c|}{ Performance Evaluation Ratings } \\
\hline \multicolumn{2}{|c|}{$1^{\text {st }} \mathrm{Yr}$} & \multicolumn{2}{c|}{$2^{\text {nd }} \mathrm{Yr}$} & \multicolumn{2}{c|}{$3^{\text {rd }} \mathrm{Yr}$} \\
\hline Dec & June & Dec & June & Dec & June \\
\hline 5.92 & 6.79 & 5.81 & 5.36 & 7.29 & 8.53 \\
\hline
\end{tabular}
with your performance evaluations - she seems fair and has been very consistent with how she approaches the evaluation. The trouble is that she doesn't seem to cut you a break when there are reasons for problems that come up. Maybe that's because she isn't here to see what is going on. But, she has been pretty supportive otherwise of you over the three years. You really have no complaints except for not working directly with her. That bothers you.

You are married but do not have children. You resent it when other analysts get time off to deal with their kids. You don't have to request that time. You don't think your boss takes that into account. Overall, you feel you have a shot at the promotion.

Supervisor: 054 (Jennifer)

Copyright (c) 2013 Institute of Behavioral and Applied Management. All Rights Reserved. 


\section{Pernicious Performance Appraisals}

Coworker: Terry

Employee ID No. : 3545 TERRY

You were hired 3 years ago to be a financial analyst for xyz corp. When you were hired, it was made very clear that four other analysts were hired with the intention to let one of you go after 3 years. This is a competitive company and it wants only the best people. They have zero tolerance for poor performance.

It is now time for the company to make the decision as to who gets fired. You also find out that one of your cohort will be selected for promotion to a supervisory position; this comes with a $20 \%$ raise and a $\$ 10,000$ bonus.

You and your boss get along very well. She has been very supportive of you over the years. But she's not treating you differently - she is supportive of her entire staff. Your only complaint, and it's minor, is that she doesn't

\begin{tabular}{|c|c|c|c|c|c|}
\hline \multicolumn{5}{|c|}{ Performance Evaluation Ratings } \\
\hline \multicolumn{2}{|c|}{$1^{\text {st }} \mathrm{Yr}$} & \multicolumn{2}{|c|}{$2^{\text {nd }} \mathrm{Yr}$} & \multicolumn{2}{c|}{$3^{\text {rd }} \mathrm{Yr}$} \\
\hline Dec & June & Dec & June & Dec & June \\
\hline 5.92 & 5.45 & 6.41 & 5.85 & 3.80 & 6.75 \\
\hline
\end{tabular}
always appreciate that you can't always control your performance. If a project goes sour she tends to blame you and you don't think that's fair. But this is really minor. You can't complain.

In fact, the few times you've needed time off during the day to pick up your kid at school, she has been very understanding. She didn't even ask that you make up the time. Yes, you're sitting in a good position. You may even get that promotion.

Supervisor: 054 (Jennifer)

Coworker: Peter

Employee ID No. : 3546 NEIL

You were hired 3 years ago to be a financial analyst for xyz corp. When you were hired, it was made very clear that four other analysts were hired with the intention to let one of you go after 3 years. This is a competitive company and it wants only the best people. They have zero tolerance for poor performance.

It is now time for the company to make the decision as to who gets fired. You also find out that one of your cohort will be selected for promotion to a supervisory position; this comes with a $20 \%$ raise and a $\$ 10,000$ bonus.

Your boss seems the type to make up his mind quickly and stick to it. You and he hit it off on the first day and you've gotten along ever since. He has been very supportive and understanding over the three years. You have not always

\begin{tabular}{|c|c|c|c|c|c|}
\hline \multicolumn{5}{|c|}{ Performance Evaluation Ratings } \\
\hline \multicolumn{2}{|c|}{$1^{\text {st }} \mathrm{Yr}$} & \multicolumn{2}{|c|}{$2^{\text {nd }} \mathrm{Yr}$} & \multicolumn{2}{c|}{$3^{\text {rd }} \mathrm{Yr}$} \\
\hline Dec & June & Dec & June & Dec & June \\
\hline 5.39 & 5.81 & 5.56 & 5.40 & 6.65 & 6.05 \\
\hline
\end{tabular}
succeeded in your projects but your boss has actually pointed out reasons for the failure that were outside your control. Now that's impressive! You consider him a fair and excellent supervisor. You think you have a shot at that promotion. Your only concern is that, as a bachelor, you've had some rough mornings after a night out.

Supervisor: 038 (Mark)

Coworker: Mary 


\section{Group Rating Summaries}

Group 1

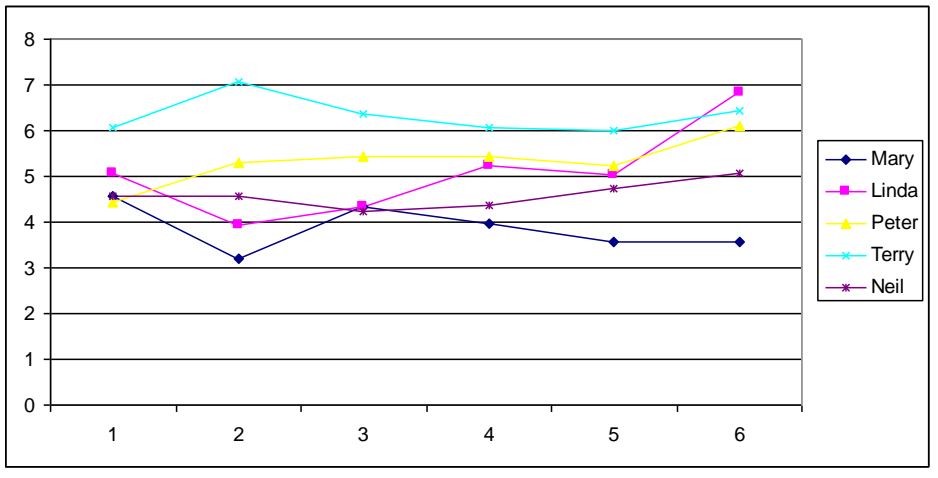

Group 2

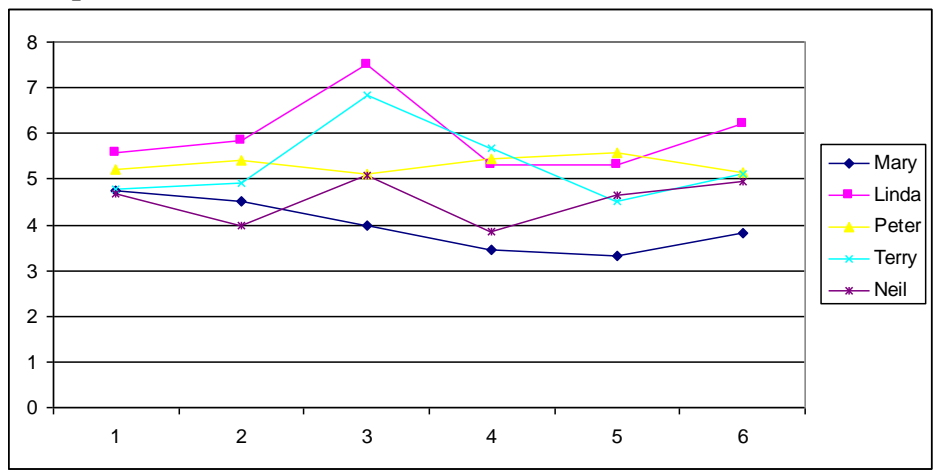

Group 3

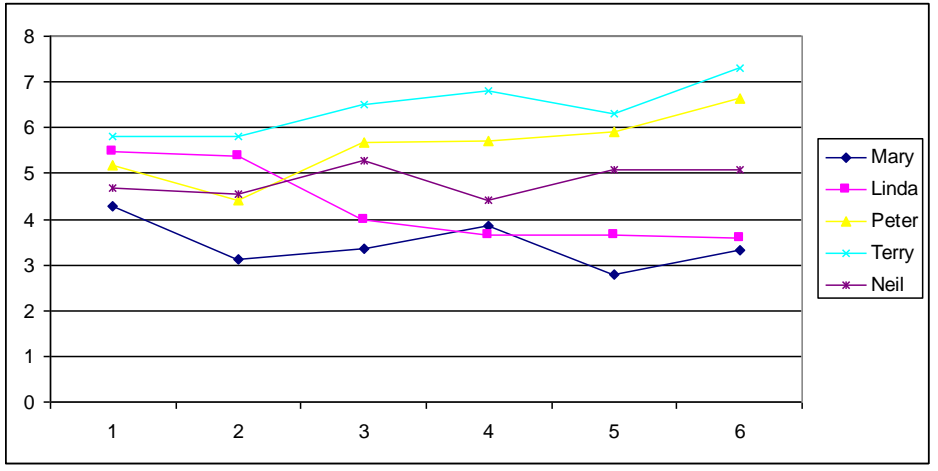

Group 4

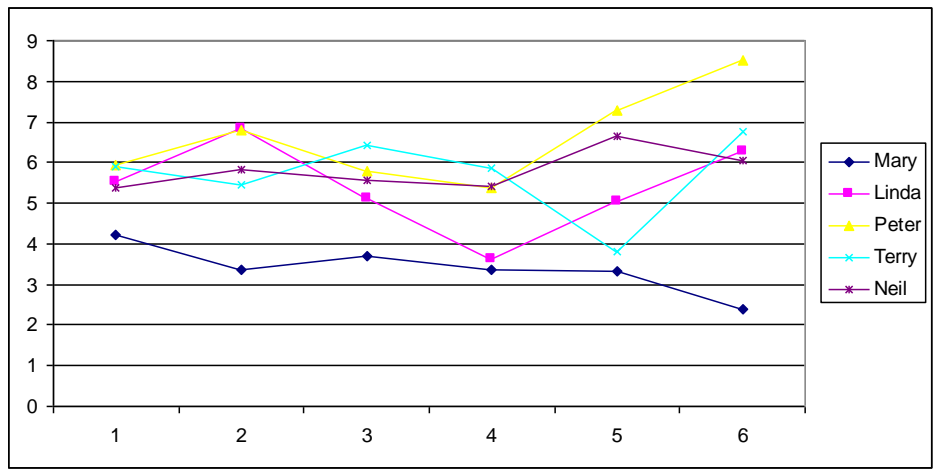

Copyright (c) 2013 Institute of Behavioral and Applied Management. All Rights Reserved. 


\section{Pernicious Performance Appraisals}

\section{VP Decision Form}

Vice President:

Group 1

\begin{tabular}{|l|l|l|l|}
\hline Action & ID No. & Name & Rationale \\
\hline Fire: & & & \\
\hline Promote: & & & \\
\hline $10 \%$ Raise: & & & \\
\hline $4 \%$ Raise: & & & \\
\hline No Raise: & & & \\
\hline
\end{tabular}

Notes: 